\title{
Review
}

Iseult Lynch*, Arti Ahluwalia, Diana Boraschi, Hugh J. Byrne, Bengt Fadeel, Peter Gehr, Arno C. Gutleb, Michaela Kendall and Manthos G. Papadopoulos

\section{The bio-nano-interface in predicting nanoparticle fate and behaviour in living organisms: towards grouping and categorising nanomaterials and ensuring nanosafety by design}

\begin{abstract}
In biological media, nanoparticles acquire a coating of biomolecules (proteins, lipids, polysaccharides) from their surroundings, which reduces their surface energy and confers a biological identity to the particles. This adsorbed layer is the interface between the nanomaterial and living systems and therefore plays a significant role in determining the fate and behaviour of the nanoparticles. This review summarises the state of the art in terms of understanding the bio-nano interface and provides direction for potential future research and recommendations for future priorities and strategies to support the safe implementation of nanotechnologies. The central premise is that nanomaterials must be studied as biological entities under the appropriate exposure conditions and that this should be implemented in study design and reporting for nanosafety assessment. The implications of the bio-nano interface for nanomaterials fate and behaviour are described in light of four interlinked perspectives: the Coating concept; the Translocation concept; the Signalling concept, and the Kinetics concept. A key conclusion is that nanoparticles cannot be viewed as non-interacting species, but rather must be thought of, and studied as, biological entities, where their interaction with the environment is mediated by the proteins and other biomolecules that adsorb to them, and the key parameter to characterise then becomes the nature, composition and evolution of the bionano interface.
\end{abstract}

Keywords: biological identity; biomolecule corona; bionano interface; nanomedicine; nanoparticle; nanosafety; synthetic identity.

\footnotetext{
*Corresponding author: Iseult Lynch, Department of Geography, Earth and Environmental Sciences, University of Birmingham, Edgbaston, Birmingham, B15 2TT, UK, E-mail: i.lynch@bham.ac.uk Arti Ahluwalia: Research Center "E. Piaggio", Faculty of Engineering, University of Pisa, via Diotisalvi 2, 56126 Pisa, Italy
}

Diana Boraschi: Institute of Protein Biochemistry, National Research Council, Via Pietro Castellino 111, 80131 Napoli, Italy Hugh J. Byrne: Focas Research Institute, Dublin Institute of Technology, Camden Row, Dublin 8, Ireland

Bengt Fadeel: Institute of Environmental Medicine, Karolinska Institutet, Nobels väg 13, S-171 77 Stockholm, Sweden

Peter Gehr: Institute of Anatomy, University of Berne, Baltzerstrasse 2, $\mathrm{CH}-3000$ Bern 9, Switzerland

Arno C. Gutleb: Department of Environment and Agro-

biotechnologies, Centre de Recherche Public - Gabriel Lippmann, 41, rue du Brill, L-4422 Belvaux, Luxembourg

Michaela Kendall: School of Chemical Engineering, University of Birmingham, Edgbaston, Birmingham, B15 2TT, UK

Manthos G. Papadopoulos: National Hellenic Research Foundation, 116-35 Athens, Greece

\section{The bio-nano interface - providing a biological identity to nanomaterials}

The role of nanoparticle interaction with biological molecules as the key to nanomedicine and nanotoxicity has emerged recently [1], with the development of the idea of the nanoparticle-protein or biomolecule corona [2]. This is the dynamic layer of proteins and other biomolecules that adsorbs to nanoparticle surfaces immediately upon contact with living systems and is what organisms or cells "see" and interact with [3]. Unlike bulk biomaterials, however, the fact that nanoparticles are sufficiently small that they can reach sub-cellular locations results in significant new potential impacts, specifically in terms of their interactions with biomolecules and biomembranes. The consequences of this for nanoparticle uptake and biodistribution and nanoparticle-induced signalling impacts need to be considered. A recent review of nanoparticles interacting with biological systems suggests that nanoparticles are mobile solids, combining the properties of 
solids (for example, fluorescence in the case of quantum dots where the constituent components are non-fluorescent) with the ability to thermally diffuse (a property of molecules) [4]. Their large surface area allows them to act as a scaffold for protein and biomolecule binding, leading nanoparticles to acquire a biological identity, or a bionano interface. The nanoparticle protein or biomolecule corona hypothesis suggests that the biomolecules (proteins, lipids, nucleic acids etc.) that reside on the particle determine its biological identity and subsequent impacts [3]. The view is thus emerging that one should correlate the properties of the nanoparticle corona or its bio-nano interface to the biological activity/responses rather than simply the bare nanomaterial properties [5].

It is clear that the biological behaviour and consequences of nanoparticles are largely dictated by how they interface to biology. The idea of airborne particulates becoming coated with lung surfactant lipid following inhalation was postulated in 1990 [6]. Proteins and lipids in lung lining liquid at the air-liquid (alveolar fluid, hypophase) interface - the first biostructure an inhaled nanoparticle encounters when deposited in the alveoli - were later observed to coat urban nanoparticles in a corona and cause nanoparticle aggregation [7-9].

This lung-surfactant corona was later proposed as an important protective mechanism mediating the health impacts associated with breathing in airborne particles and nanoparticles in urban air [10]. Despite early evidence of particle coronas in the lung identified using newly developed atomic and molecular scale techniques [11], the biological interface remains the least understood aspect about nanoparticles, and classification systems to characterise the outermost layers of the bio-nano interface, i.e., those biological signatures that are available to engage endogenous cellular machinery, are absent. By far the most studied component of the corona is the protein composition [7, 12], but lipids, sugars and other species likely also play a role [13-15]. Thus, despite the importance of the bio-nano interface, and the fact that it potentially holds the key to both safe implementation of nanotechnologies and nanomedicine, efforts to characterize it are surprisingly scarce [16]. While the focus of this review is on biomolecules such as proteins and lipids, the ideas are equally applicable to nanoparticles dispersed in environmental milieu, where decaying plant and animal matter results in so-called natural organic matter, typically composed of polysaccharides, interact with nanoparticles affecting their stability, dispersability and environmental fate and behaviour [17, 18, 19].

Significant advances have been made in the last 5 years, both in understanding of the importance of the bionano interface and in terms of methods and approaches to study it. Evidence for this wide scale acceptance of the concept of the nanoparticle biomolecule corona and the importance of the bio-nano interface comes from the fact that the OECD Sponsorship Programme has included characterisation of nanoparticles in biofluids as part of their list of endpoints at the end of 2010 [20].

Before getting into the details of the state of the art and recommendations for moving beyond this it is important to note that interactions between nanoparticles and biomolecules, and the formation of the bio-nano interface, has consequences for both the nanoparticle surface itself, and potentially also for the proteins and other biomolecules contained in the biomolecule corona. A summary of some of these effects, and reviews or key publications relating to these effects, are given in Table 1.

The emerging discipline of nanotoxicology may be viewed essentially as the study of the undesirable interference between man-made nanomaterials and cellular nanostructures or nanomachines [35]. In parallel, the considerable allure of engineered nanoparticles for clinical applications is due to the fact that these artificial

Table 1 Nanoparticle-biomolecule interactions and the formation of the bio-nano interface has consequences for both the adsorbed biomolecules and for the nanoparticle surface and dispersion.

\begin{tabular}{lc}
\hline Effect of adsorption on Biomolecules: & Effect of interaction on Nanoparticles: \\
\hline - conformation changes $\rightarrow$ blocked or enhanced presentation & - conferring a biological identity - altered interaction/uptake and \\
of active sites and subsequent functional changes [21, 22] & biodistribution [23-25] \\
- altered propensity for protein-protein interactions (e.g., & - altered surface characteristics and thereby stability and dispersability \\
fibrillation) [26] & {$[8,27]$ and potentially also dissolution potential (as per environmental } \\
& macromolecules such as humic acids) although limited literature [28] \\
- oxidative effects - lesions, post-translational effects, & - reduced surface energy/reactivity [30] (possibly only temporarily) \\
etc. [29]. & - masking targeting or other bio-functional elements? (possibly only \\
- depletion of medium components which can result in & temporarily) [32] \\
$\begin{array}{l}\text { indirect toxicity effects [8, 10, 31] } \\
\text { - altered kinetics (distribution, half-life, degradation, etc.) }\end{array}$ & - Altered bioactivity [23, 34] \\
[21,33] & \\
\hline
\end{tabular}


entities are designed to interact with biological systems at the nano-scale. Moreover, understanding and controlling the bio-nano-interface is equally important both from a nanomedicine and nanotoxicology point of view. In fact, a recent study reported that the adsorption of serum proteins obscures targeting ligands grafted to nanoparticles (in this case: transferrin) thereby preventing targeted uptake, as shown schematically in Figure 1 [32]. This demonstrates the importance of biomolecular interactions in determining nanoparticle uptake, uptake mechanism and fate and behavior in living systems. It is important to note that the size ratio between nanoparticle and proteins plays a vital role in determining nanomaterial-protein (macromolecule) interactions, and indeed for many types of inherently small nanomaterials (e.g., Quantum
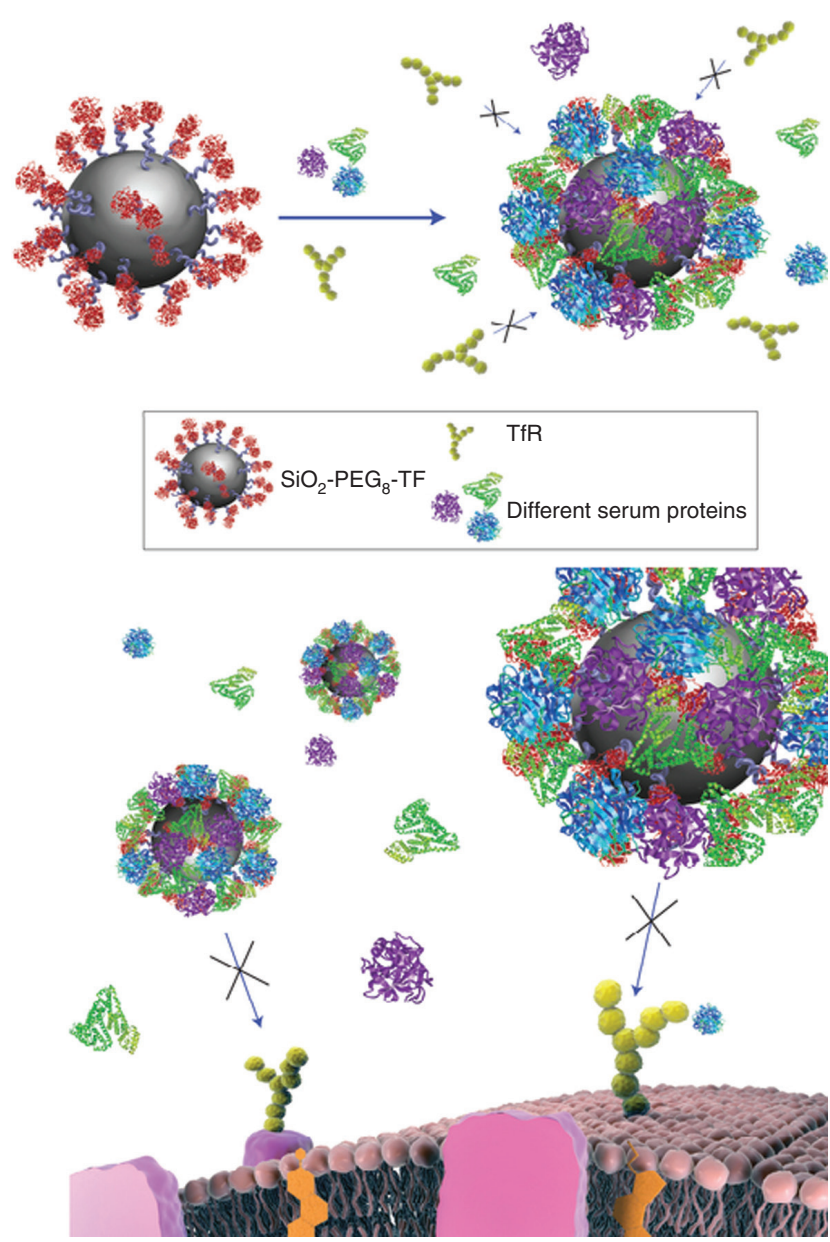

Figure 1 The biomolecule corona masks targeting ligands: Transferrin-functionalised nanoparticles lose their targeting capabilities when a biomolecule corona adsorbs on the surface. Schematic representation of loss of TfR targeting for Tf-conjugated nanoparticles in the presence of FBS proteins (endogenous Tf, where present, could also compete for TfR). Reproduced from [32]. Note that the particles in this schematic are intended to represent $\sim 50 \mathrm{~nm}$ particles, but that the nanoparticles and proteins are not drawn to scale. dots which are typically $<5 \mathrm{~nm}$ ) the nanomaterials may be smaller than the proteins, as discussed in Klein et al. [36] and demonstrated by Deng et al. in their study of the role of gold nanoparticle size on binding to fibrinogen, whereby small changes in nanomaterial size (from $8 \mathrm{~nm}$ to $10-12 \mathrm{~nm}$ to $15 \mathrm{~nm}$ ) resulted in significant differences in how the protein and nanomaterials interacted [37]. The schematic figures in this manuscript (taken from the literature) are not drawn to scale, but are intended only to illustrate the principles and concepts being described.

The fact that many endogenous transport and other processes utilise biomolecule clusters in the nanoscale, such as the lipoprotein complexes, e.g., chylomicrons ( $>100 \mathrm{~nm}$ ) and High Density Lipoproteins (8-10 nm), and ribosomes (DNA and protein clusters; $25-30 \mathrm{~nm}$ ), suggests that in many cases nanoparticles may simply be recognised as scaffolds onto which biomolecules can adsorb as part of the normal functioning of the biomolecules [38]. Indeed, most spherical nanoparticles studied to date have been shown to bind lipoproteins, often with a size and surface curvature influence, in addition to a compositional influence, such as from surface charge [21].

Building on this background and the current state of the art, we suggest some potential future research directions and make recommendations for future priorities and strategies to ensure that the importance of the bionano interface is recognised. Central to this is the fact that nanomaterials must be studied as biological entities under the appropriate exposure conditions, and that this approach must be implemented in study design and reporting for nanosafety assessment. The implications of the bio-nano interface for nanomaterials fate and behaviour are described from four primary perspectives:

- the Coating concept,

- the Translocation concept,

- the Signalling concept,

- the Kinetics concept.

In this paper we considered that the principles outlined hold for all nanoparticles types, and thus the examples cited from the literature may refer to metallic, metal oxide, carbon based, polymer coated or polymeric nanoparticles, quantum dots etc. Clearly surface chemistry matters, as does size and shape, in terms of the finer details of how each different particle type behaves, but we believe that the principles hold generally and indeed that these could form the basis of a future classification strategy that is independent of nanomaterial composition or structure. The four primary perspectives presented here align well with, and indeed expand upon, the three "principles of nanotoxicology" described by Krug and Wick, namely the 
Transport Principle, the Surface Principle and the Material Principle [39] and focus on the role of biomolecules in providing a crucial interface between nanoparticles themselves (which are seen more as scaffolds for protein/biomolecule binding) and biological systems. Indeed, a key conclusion is that nanoparticles must be thought of, and studied as, biological entities, where their interaction with the environment is mediated by the proteins and other biomolecules that adsorb to them, and the key parameter to characterise then becomes the nature, composition and evolution of the bio-nano interface.

\section{The coating concept: Interactions of nanoparticles with proteins, lipids, polysaccharides, DNA/RNA, natural organic matter, etc.}

Scientists increasingly recognise that nanoparticles immediately absorb proteins and/or other biomolecules from their surroundings to lower their surface free energy [40] with important consequences for nanoparticle stability in dispersion [41], and interaction with biological systems. Protein binding to nanoparticles changes both the hydrophobicity of the outermost surface (the bio-nano interface) and the effective surface charge, with even very positively charged nanoparticles typically presenting a neutral to slightly negative zeta potential in plasma or cell culture medium containing foetal calf serum. Note that for ecotoxicological studies, natural organic matter plays much the same role as proteins for in vitro and in vivo toxicology studies, modulating the nanoparticle surface (free energy) and thus the dispersibility of nanomaterials [18] and interaction with biological systems. As a consequence, nanoparticles dispersed in biofluids containing proteins, lipids, polysaccharides, etc. can have a very different dispersion profile than the same nanoparticles dispersed in reference buffers, which can lead to very different effective or available doses of nanoparticles for interaction with living systems $[3,5]$. The understanding that nanoparticles in a biological medium are remarkably strongly associated to a biomolecular layer (rich in proteins in vivo) drawn from their environment shifts the focus of studies and discussions away from the bare material identity to a new, more nuanced, conception in which particle size, shape and corona expression (collectively the bio-nano interface) are more likely to be the defining features of nanomaterial biological identity and consequently fate and behaviour. Thus, in addition to describing the physico-chemical properties (the so-called "Synthetic identity"), a "biological" property should be added to describe the nanoparticles as they exist in the relevant exposure context [42], as shown in Figure 2.

The composition of the biomolecule corona, and the subsequent evolution as a particle moves from one biological environment to another [44], available dose and consequent biological interactions of the coated nanoparticles, have been found to depend on the specific details of the biofluid in which the nanoparticles are dispersed, which may account for much of the contradictory reports present in the literature for nominally identical materials to date [5]. Thus, the same (batch of) nanoparticles dispersed in different cell culture media (e.g., DMEM or RPMI) containing identical concentrations of Foetal Bovine Serum (FBS) from the same batch have been shown to result in quite different coronas, both in terms of their thickness and dynamics [25]. The authors of that study observed that DMEM elicits the formation of a large time-dependent protein corona, while RPMI shows different dynamics with reduced protein coating. These different coronas, which resulted from the different ionic strengths and salt compositions of the media, had implications for uptake and impact, with the protein-nanoparticle complexes formed in RPMI being more abundantly internalized in cells as compared to protein-nanoparticle complexes formed in DMEM, consequently exerting overall stronger cytotoxic effects [25]. These results suggest that cell culture medium composition and ionic strength can alter adsorption of proteins onto the nanoparticle surface, which can impact on the particle agglomeration and potentially alter the

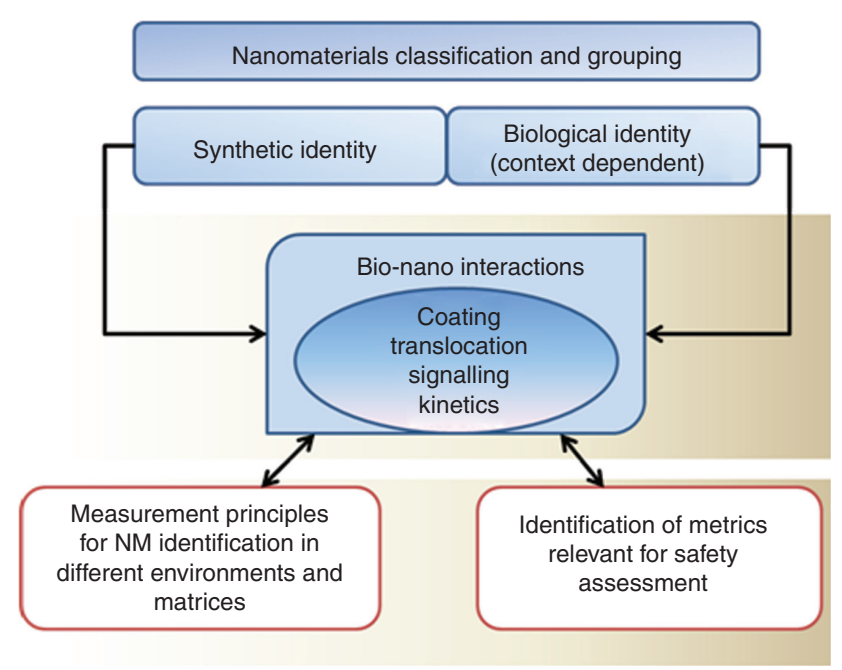

Figure 2 The importance of understanding the inter-relationship between the synthetic and biological identities of nanomaterials for hazard assessment, identification and classification of nanomaterials). Figure re-drawn from the NanoSafety in Europe 2015-2025 report [43]. 
available dose of nanoparticles under the different exposure conditions. However, in the absence of characterisation of the nanoparticles in the two different media, it is not possible to make any interpretation of the data on the basis of whether the different protein coronas result in different available doses, which could potentially explain the different observed impacts [5]. In other studies, the surface chemistry profiles of airborne particle samples collected in different continents, and exposed to the lung lining liquid of different subjects, showed surprising consistency and resulted in similar aggregation effects [9].

Similar data resulted from comparison of corona composition and cellular uptake of nanoparticles dispersed in cell culture media containing 10\% foetal calf serum that had either been heat inactivated (to remove the complement proteins) or not heat inactivated [24]. Here also, the particles with the lower protein content in their coronas entered cells more effectively than those with higher protein content in their coronas $[24,45]$. Related work has shown that the composition of the nanoparticle biomolecule corona can depend on the ratio of nanoparticle surface area to available proteins, with the consequence that nanoparticle coronas prepared under conditions typical for in vitro testing (i.e., $3 \%-10 \%$ serum proteins in medium) may not be representative of the corona that would form under in vivo conditions (typically $55 \%-80 \%$ proteins) [30].

A study of the interaction of nanoparticles with surfactant protein A (SP-A), a significant protein component of alveolar lining fluid, found different particle-protein interactions for each of eight different nanoparticles [46]. Interestingly, three variants of the same material (cerium dioxide nanoparticles) revealed different adsorption patterns despite the materials being nominally identical and indistinguishable in electron microscopy images [46]. This suggests that the biomolecule corona composition, or the details of the bio-nano interface, could be a very sensitive tool to distinguish subtle material differences and to predict biological impacts, once correlations between adsorbed biomolecules and signalling or other effects are confirmed. In contrast, surfactant protein D (SP-D) alters cellular uptake in a different way [47].

Multiple studies have assessed the effect of nanoparticle composition [38, 48, 49], size [49, 50], surface coating $[51,52]$, shape and other physico-chemical parameters on the nature and composition of the protein corona. Recent reviews have attempted to summarise the many factors that have been found to influence protein-nanoparticle interactions [53, 54], and have described these factors as falling into three categories: protein (or macromolecule)related (molecular weight, isoelectric point (pI), and conformational flexibility), NM-related (species, size, shape, charge, roughness, hydrophobicity, crystallization, defects, and functionalization), and medium-related ( $\mathrm{pH}$ and ion strength) [54].

In the case of nanoparticles dispersed in the environment, interaction with environmental organic matter and biological molecules has been shown to determine their subsequent effects and fate in a similar manner. Some studies have shown that nanoparticles can adsorb natural organic matter to form complexes and, as a consequence of such coating, they may become negatively charged, altering their fate and transport in the aqueous environment $[55,56]$. Humic acids are a major part of the natural organic matter contained in soil and fresh water. Their structure, which consists of a skeleton of alkyl/aromatic units crosslinked mainly by oxygen and nitrogen groups with the major functional groups being carboxylic acid, phenolic and alcoholic hydroxyls, ketone and quinine groups, allows them to behave as surfactants, with the ability to bind both hydrophobic and hydrophilic materials [57]. As a consequence of this behavior, nanoparticle-humic acids interactions should be a factor of relevance in the study of the life cycle of nanomaterials, and likely natural organic matter plays a similar role in the environment that proteins do for human health.

We thus propose that it is vital that nanomaterials be considered as biological entities, and studied as such. ${ }^{1}$ Key steps in the short to medium term include understanding and eventually predicting which chemical, geometrical and physico-chemical parameters of nanomaterials lead them to preferentially adsorb which proteins, and connecting the absorbed proteins with observed impacts, such as uptake, localization and signaling. For example, the role of opsonins and dysopsonins is well understood in terms of phagocytic recognition [58, 59]. However, much work is required to tease out the signaling pathways influenced by biomolecules contained at the bio-nano interface, whether these be functioning normally or experiencing altered functionality as a result of conformation changes induced by binding to the surface.

\section{The translocation concept: interactions of nanomaterials with cells, tissues, barriers, etc.}

The human body has four portals of entry for nanoparticles: three natural portals, the lung, the digestive tract and

1 http://www.skep-network.eu/Libraries/Network_documents/ SKEP_Nanomaterials_in_REACH_Report.sflb.ashx. 
the intact skin, and one artificial portal, the veins, into which nanoparticles can be injected. It has been shown that nanoparticle translocation into capillaries leads to their translocation into other organs [60-65], and evidence is emerging that the route of entry, and the biomolecules that form the initial corona at the site of entry (e.g., plasma proteins following injections versus lung surfactant proteins following inhalation), play a distinct role in determining the organ biodistribution of nanoparticles [66]. For example, accumulation of $\mathrm{TiO}_{2}$ nanoparticles in the brain was 100-fold higher for particles entering via lung than for those injected directly into the bloodstream (Personnal Communication W.G. Kreyling). Further evidence for the importance of the initial bio-nano interface, which is determined by the route of exposure, comes from a study of the interaction of magnetite nanoparticles (110-180 nm in diameter), coated with different polymers (starch, carboxymethyldextran, chitosan, poly-maleic-oleic acid, phosphatidylcholine), with alveolar macrophages [67]. Cellular binding and uptake of nanoparticles by alveolar macrophages was increased for nanoparticles treated with SP-A, whereas albumin, the prevailing protein in plasma, led to a significant decrease. This study provides evidence that, after inhalation of nanoparticles, a different protein coating and thus different biological behavior may result compared to direct administration to the bloodstream [67].

A direct effect of biomolecule corona composition on nanoparticle biodistribution has been shown in an elegant study using radiolabelled gold nanoparticles of five different sizes $(1.4,5,18,80$, and $200 \mathrm{~nm})$ and $2.8 \mathrm{~nm}$ gold nanoparticles with opposite surface charges following intravenous injection into rats [68]. Results indicated that both size and surface charge of nanoparticles strongly determined the biodistribution, with different charge particularly leading to significantly different accumulations in several organs. The authors concluded that the alterations of accumulation in the various organs and tissues, depending on nanoparticle size and surface charge, were mediated by dynamic protein binding and exchange [68].

When interacting with cells, nanomaterials come into close contact with the cell membrane, a dynamic structure that segregates the chemically distinct intracellular milieu (the cytoplasm) from the extracellular environment by coordinating the entry and exit of small and large molecules. Macromolecules are carried into the cells in membrane bound vesicles derived from the invagination and pinching-off of pieces of the plasma membrane to form endocytic vesicles. This process, termed endocytosis, has different features depending on the size and type of the molecule/structure internalized: receptor-independent endocytosis (fluid-based endocytosis and macropinocytosis), and several types of receptor-dependent endocytosis (clathrin-dependent, lipid-raft-independent, lipid raft-dependent/caveolaeindependent, and caveloae-dependent). These endogenous processes are exploited by bacteria and viruses for invading cells, and it is likely that also nanoparticles may enter cells through them, although there are quite conflicting reports as to the exact mechanism(s) mediating cell entry by different nanoparticles [69-72]. Very likely this is a result of different bio-nano interfaces. A recent review of cellular uptake of nanoparticles describes work revealing active endocytosis mechanisms and pathways involved in their cellular uptake, and summarises the current state of knowledge: Interested readers are referred here for more details [73]. All endocytic pathways have a feature in common, in that the particle, which entered the cell, is finally located in an intracellular vesicle, typically the lysosome, as the final sub-cellular destination [74-76]. However, there are studies, which reported the intracellular localization of nanoparticles that were not membrane bound, suggesting alternative pathways for particles to enter, or that the nanoparticles can escape the endosomes, as a result of endosomolysis [77-80]. This alternative way of nanoparticle penetration into cells, i.e., through the cell membrane, has been called "adhesive interaction" (by van der Waals and other forces) and has been suggested as an alternative mechanism of passive entry [81]. Another recent publication offers convincing evidence for a passive mechanism whereby nanoparticles enter cells by membrane penetration on an experimental and calculation basis [80]. The fact that nanoparticles are found free in the cytoplasm following uptake via the adhesive mechanism is noteworthy, since free nanoparticles in the cytoplasm may cause cellular effects different from those contained in vesicles (which entered the cell probably by an endocytic mechanism). Moreover, the intracellular trafficking may be different and also interaction with intracellular structures like the cytoskeleton, the organelles and the nucleus may be via direct contact for free nanoparticles. These aspects may all contribute to the different reactions of the cell to different nanoparticles, and are worthy of further investigation.

Very significant modulatory effects of proteins and the bio-nano interface have been observed in terms of nanoparticle uptake by human macrophages, by undifferentiated and by PMA-differentiated monocytic THP-1 cells of $50 \mathrm{~nm}$ and $100 \mathrm{~nm}$ fluorescently-labelled carboxyl- or amine- modified polystyrene nanoparticles from medium with and without (serum free medium) serum proteins 
[59]. The amount of internalized nanoparticles, the uptake kinetics, and its mechanism were critically dependent on particle opsonization by serum proteins, with nanoparticles being rapidly internalized by cells in serum-free (SF) medium until they reached saturation kinetics, whereas in 10\% human $\mathrm{AB}$ serum-enriched (SE) medium the nanoparticle uptake rate was drastically reduced as the uptake was via receptor-mediated processes [59]. Thus, in terms of understanding nanoparticle uptake and biokinetics, the bare material surface is clearly the wrong parameter to use, and indeed uptake studies in the absence of an appropriate biomolecule environment report on uptake as a result of membrane damage in an artefactual situation [34], rather than on nanoparticle uptake utilising endogenous pathways.

However, one important question that remains to be answered is whether the protein and biomolecule layer on the nanoparticle surface mediates the binding to cells through one or more specific active mechanisms or via non-specific interactions, whereby the biomolecules behave as a simple coating which reduces the surface energy of the nanoparticles. There are considerable differences in interpretation in the literature to date regarding uptake mechanisms, and approaches such as poisoning the endocytic receptors using pharmacological inhibitors or silencing of selected proteins involved in specific endocytic pathways (e.g., clathrin or caveolin) suggest that the same nanoparticle might exploit different uptake mechanisms to enter different cell types or indeed the same cell type under different conditions [82]. Similar results have been reported for nanoparticles engineered for targeting the folate receptor: folate receptorspecific siRNA was used to reduce folate receptor levels and uptake of heparin-folate-paclitaxel nanoparticles by target cells, but silencing only reduced uptake to half of its value in the control cells, suggesting multiple pathways of uptake [72]. A recent study of differently surface modified $100 \mathrm{~nm}$ polystyrene nanoparticles indicated that different specific protein coronas did not result in differential association of the particles to endothelial cells, suggesting that binding and cellular uptake by these cells may not be triggered by interaction of the protein corona with specific receptors [83]. The authors suggested that an assessment of the adsorptive capacity of nanoparticles could be useful in order to predict the magnitude of nanoparticle cellular interactions. Much of the success to date in terms of nanoparticles for drug delivery has been the result of fortuitous absorption of endogenous transporter proteins, such as Apolipoprotein E, to nanoparticles, or deliberate functionalisation of nanoparticles with these proteins $[84,85]$.
Once it is recognised that the biointerface is the key parameter to understand in terms of determining mechanisms of uptake of nanomaterials, a key question becomes how researchers can target nanoparticles to best utilise these pathways, and simultaneously avoid non-specific protein interactions, by designing the bio-nano interface. Several recent reviews highlight the various endogenous uptake pathways available to nanomaterials, and examples of therapeutic strategies that could potentially utilise these pathways $[86,87]$. Indeed, there has been considerable effort devoted to development of targeting nanoparticles, such as conjugation of $100-\mathrm{nm}$ polystyrene nanoparticles with glycocalicin, which significantly increased the particle adhesion on P-selectin-coated surfaces and cellular uptake of nanoparticles by activated endothelial cells under physiological flow conditions [88], or functionalisation of cerium oxide nanoparticles with transferrin (Tf), to increase preferential uptake by transferrin receptor (TfR) over-expressing human lung cancer cells (A549) and normal embryo lung cells (WI-38) [89]. A key finding from this work is that the strength of interaction between the nanoparticles and the targeting protein (Tf in this case) can be tuned by modifying the surface charge of the nanoparticles, and that binding energy values could be correlated with cellular uptake (as shown schematically in Figure 3) [89], in a first step towards quantitative structure-activity relationships (QSARs).

The task of modeling, and ultimately predicting, the distribution and fate of nanoparticles represents an interesting, and quite new challenge [76]. A flux-based approach, based on live cell imaging of fluorescent nanoparticle uptake and transport in a time resolved manner has shown that the nanoparticles rapidly localize to endosomes $(1 \mathrm{~h}$ ) and later to lysosomes (by $4 \mathrm{~h}$ ), with no evidence of nanoparticles exiting from lysosomes once they have arrived there [76]. The observed decrease in fluorescence over time was shown to correlate with cell division, and with the nanoparticle load being split evenly between the two daughter cells. While vesicle recycling is a normal part of cell homeostasis, no recycling of fluorescent nanoparticles from vesicles was observed in the above study [76]. Indeed, another study has shown that relatively few 40 or $100 \mathrm{~nm}$ carboxylicmodified polystyrene nanoparticles are able to access endocytic recycling pathways, as judged by the lack of significant co-localization with Rab11, a key protein associated with recycling vesicles [90]. There is no evidence that corona-driven export processes exist for nanoparticles (unless specifically engineered to express an export signal - such as transferrin, as described below), and the chances of the appropriate specific intracellular corona 


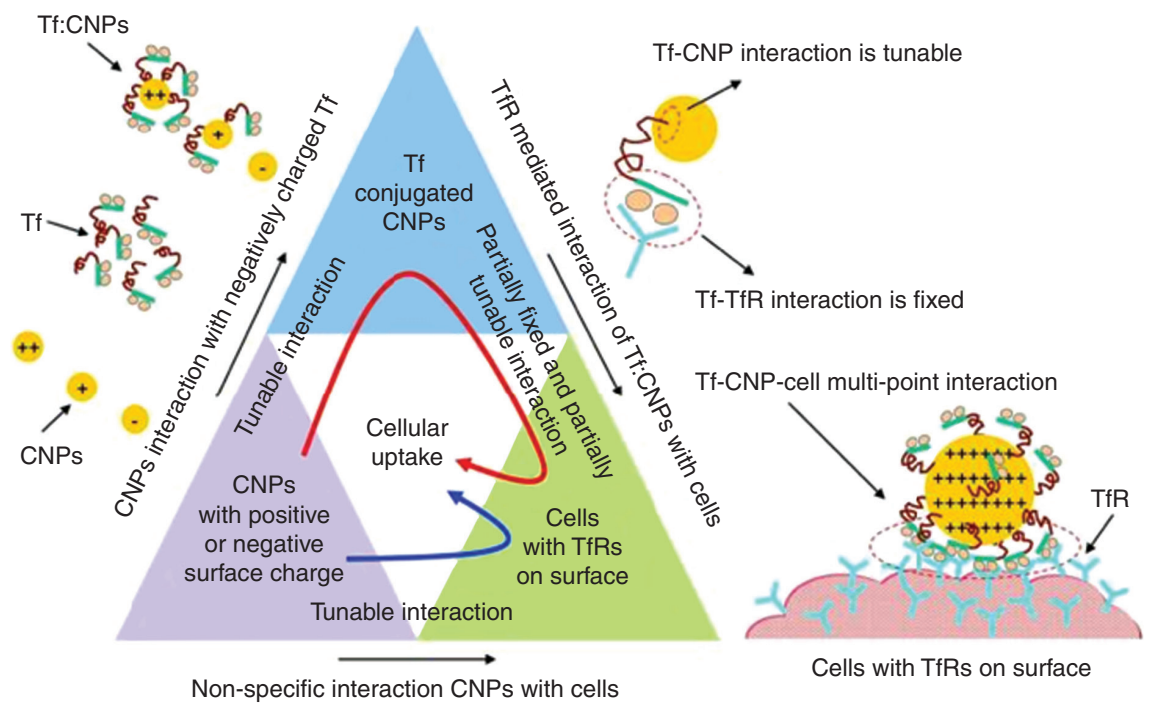

Figure 3 Schematic diagram of interaction forces acting at different stages of cellular uptake. The triangle blocks show the interaction pathways of cellular uptake of cerium oxide nanoparticles (CNPs). CNPs with strong positive charge show better adsorption of transferrin (Tf). The interaction between Tf and CNPs can be tuned by protonation; however, the interaction of Tf with TfR is fixed. CNPs with a strong positive charge lead to enhanced Tf adsorption and multiple interactions with the TfRs on the cell surface. Red curved arrow inside the triangle blocks indicates the receptor mediated cellular internalization pathway of positively charged CNPs, and blue curved arrow indicates the non-specific cellular internalization pathway of both positively and negatively charged CNPs. The red dashed circle represents the domain of multi-point interaction between Tf:CNP and TfRs on cell surface. From [89].

arising from non-specific protein binding during uptake are slim, [76] although potentially such signals could arise as a result of the nanoparticles binding peptides from the antigen processing pathways. Clearly there are some exceptions to this general rule in the case of specialized cells such as biological barriers, where translocation is a key function, such as the air-blood tissue barrier and the mucosal barriers where particle transcytosis, by epithelial and endothelial cells separated by the fused basement laminae of the two cells is common though a selective mechanism [60]. The penetration of nanoparticles through a cell (into and out, membrane bound) is called transcytosis or cytopempsis.

Single-walled carbon nanotubes (SWNT) were observed to undergo exocytosis in NIH-3T3 cells, the exocytosis rate closely matching the endocytosis rate with negligible temporal offset [91]. The exocytosis pathway was illustrated by superimposing example particle trajectories recorded in the near infrared onto the corresponding optical image of different cells [91]. Tf, which has a well-known recycling pathway, has been shown to induce exocytosis of gold nanoparticles to which it is physically adsorbed at a rate that was in linear correlation with the nanoparticle size [92]. Fifty nm was reported as the optimal cellular accumulation size for Tf-gold nanoparticles, due to the equilibration of the rates of uptake and exocytosis [92].

\section{The signalling concept: interaction of nanoparticles with major intra- cellular chemical systems}

The range and amount of nanoparticles humans are exposed to is quite significant (particularly from combustion), with the increasing production of engineered nanomaterials now contributing to this. The occupational setting is now considered as the most likely exposure route to engineered nanoparticles, but medical formulations may result in a wider population exposure [12]. The contribution of exposure to ultrafine particles such as those from combustion processes, to respiratory and skin diseases as well as more insidious and complex pathologies such as cancer and cardiovascular dysfunction, is now becoming apparent [93-95]. Their cumulative effects, or more likely the knock-on effect to neighbouring cells as well as more distant tissues and organs (i.e., paracrine signalling and cell activation) plays a key role in their toxicity at the systemic level.

A key question to consider at the outset is whether nanoparticles "signal" or merely perturb signalling pathways? Clearly sophisticated nanoparticles envisioned for biomedical applications may "signal" according to their deliberate functionalization and/or cargo of signalling molecules/drugs/genes, but it is important to consider 
whether other, pristine or non-functionalized nanoparticles "signal". The main thesis in the present review is that nanoparticles can signal by virtue of their acquired bio-corona of proteins, lipids, sugars, or other biomolecules and that studies conducted to date have not fully taken into account the "biological" identity of nanoparticles. There are certainly some (very few) examples of nanoparticles that appear to signal per se as a function of their specific size, for instance, the finding that singlewalled carbon nanotubes (SWNTs) constitute a new class of universal $\mathrm{K}^{+}$channel inhibitors that hamper channel function by fitting into the pore and thus either hindering ion movement or alternatively preventing further conformational steps [96]. We believe that further studies, using systems biology approaches, may uncover more examples of nanoparticle-mediated signaling at doses of nanoparticles that are more realistic, and that the bio-corona and, hence, the bio-nano-interface is likely to be an important determinant of such signaling. This is in distinction to the vast majority of publications to date which apply excessive amounts of nanoparticles to cells and which focus only on crude measurements of cell death.

Mapping the research agenda for investigating nanoparticle signalling effects, the research objectives can be broken down into three interlinked levels. Firstly, nanoparticles attached to the cell surface (cell membrane) may trigger a cascade of signalling processes into the cell and throughout the cell. A key question which one should ask is whether nanoparticles need to enter a cell in order to trigger/cause any effects inside the cell. While researchers have long been concerned about distinguishing between nanoparticles taken up into cells versus those adhered to the membrane for quantification of uptake [76, 97], less research has been directed to understanding nanoparticle-induced signalling from the cellular surface, which is a critical knowledge gap at present although several groups are now working on this and publications addressing this topic will appear in the literature in the near future [Personnal Communications from $\mathrm{H}$. Hofmann (EPFL) and K.A. Dawson (UCD)]. Secondly, nanoparticles can signal once they are inside single cells. Here, important aspects that need to be addressed are the manner in which nanoparticles bypass the cell membrane, enter into the cell, localise to the mitochondria and other organelles and finally the nucleus, causing changes in phenotypic function and the activation of distress signals in the form of pro-inflammatory or other molecules. The third signalling level includes the pathways by which cells communicate their response to interaction with nanoparticles to neighbouring cells and then to more distant tissues and organs through soluble mediators. A limited number of studies demonstrate paracrine signalling from nanoparticles in cells to other non-exposed cells, suggesting that such effects may occur [98-101].

At present, much of our understanding of nanoparticle induced alterations of signal transduction is limited to a very small space and time window. The question of how these adaptive signals are propagated to and translated by remote tissues and organs, how the internal milieu is modulated by them, and the signalling pathways involved in the translocation of nanoparticles from their point of uptake to distant tissues have not yet been addressed. Much of what we know of the integrative pathophysiology of engineered nanoparticles comes from animal studies focused on translocation and bioaccumulation [68, 102]. Translating the results to humans is not straightforward, and as several studies on drug toxicity have shown, caution needs to be exercised when extrapolating results from animal models to human physiology, pathology or toxicity [103]. Moreover, animal models are not amenable to decomposition of signalling dynamics in different tissues and organs. Additionally, given the degree of redundancy in signalling pathways, decoupling effects of biomolecules bound to nanoparticles from those of their unbound counterparts will be challenging. However, systems biology approaches are making significant strides here [104-106].

The induction of oxidative stress is commonly viewed as a unifying concept for understanding the cytotoxic effects of nanoparticles, such as nano-sized metal particles and their oxides as well as those produced by combustion (including from motor vehicles) [107]. However, it is also important to assess whether "oxidative stress" is merely a secondary event resulting inevitably from disruption of biochemical processes and the demise of the cell, or a specific, non-random event that plays a role in the induction of cellular damage, e.g., apoptosis? For a further discussion of these issues, readers are referred to Shedova et al. [108]. The mechanism by which oxidative damage occurs appears to be via the inhibition of electron transfer in the TCA (tricarboxylic acid) cycle and the consequent accumulation of TCA cycle intermediates. The TCA cycle is an essential metabolic network in all oxidative organisms and provides precursors for anabolic processes and reducing factors ( $\mathrm{NADH}$ and $\mathrm{FADH}_{2}$ ) that drive the generation of energy. Reactive oxygen species (ROS) are formed in the mitochondria during respiration. It has been shown that a healthy metabolic network plays a key role in the defense against oxidative stress through the production of enzymes and electron acceptors which participate in the detoxification of ROS [109]. Interference in the mitochondrial cycle results in oxidative stress 
owing to an increase in ROS, which act as second messengers to induce a cell reaction that may eventually lead to cell death. How nanoparticles cause oxidative stress and subsequent apoptotic or necrotic signalling is not clearly understood, and furthermore the process is unlikely to be the only mechanism by which nanoparticles cause cell and tissue damage [110]. Probing signalling mechanisms at the cellular level should focus on delving into the mechanisms of ROS production by nanoparticles upon entering cells, and subsequent cellular adaptation at the nuclear level (changes in gene expression) (Figure 4). It may be worth considering whether the development of oxidative stress could be a first (unspecific) reaction mechanism to foreign material intrusion. In fact, a short-lived reaction is compatible with a normal innate defensive response, which resolves rapidly with limited cell damage that is readily repaired. On the other hand, the persistence of the reaction could lead to significant damage from apoptosis and genotoxicity, and eventually to cancer. Thus, understanding the origin and kinetics of the oxidative stress induced by nanoparticles and correlating it to pathological risk could provide vital insights in the future as to the impacts of nanomaterials. Note that this theme of transience or duration of response is picked up in the "kinetics concept" section, as full understanding of mechanisms will only be possible with a proper emphasis on rate and kinetics of the various biological processes.
A detailed investigation of the mechanism of toxicity induced by $50 \mathrm{~nm}$ amine-modified polystyrene nanoparticles following uptake by 1321N1 brain astrocytoma cells found that the nanoparticles are localized in lysosomes, whereupon the lysosomal membrane becomes destabilized, likely because of the nanoparticle's positive charge, leading to release into the cytoplasm of both nanoparticles and proteolytic enzymes such as cathepsins [112]. This, in turn, results in damage to the mitochondria and activation of caspases 3 and 7, with consequent cleavage of PARP-1, ultimately resulting in the apoptotic death of the cells [112]. Ongoing work has shown that the kinetics of the lysosome membrane damage can be correlated with the digestion of the nanoparticle protein corona in the lysosomes which allows the underlying amine groups on the nanoparticles to be re-exposed [113]. Smaller, fully aminated, dendritic polymer nanoparticles have been seen to cause endosomolysis prior to transfer to lysosomes, however, and have been seen to be later localized in the mitochondria. In both stages, oxidative stress has been seen to give rise to activation of caspases, inflammatory responses and subsequent apoptotic (and other kinds of) cell death [79, 114].

An important advance in understanding nanoparticle-induced signalling and toxicity has been achieved utilising an integrated proteomics approach, as routinely used to identify protein interaction pathways, to identify the toxicity pathways and networks that are associated

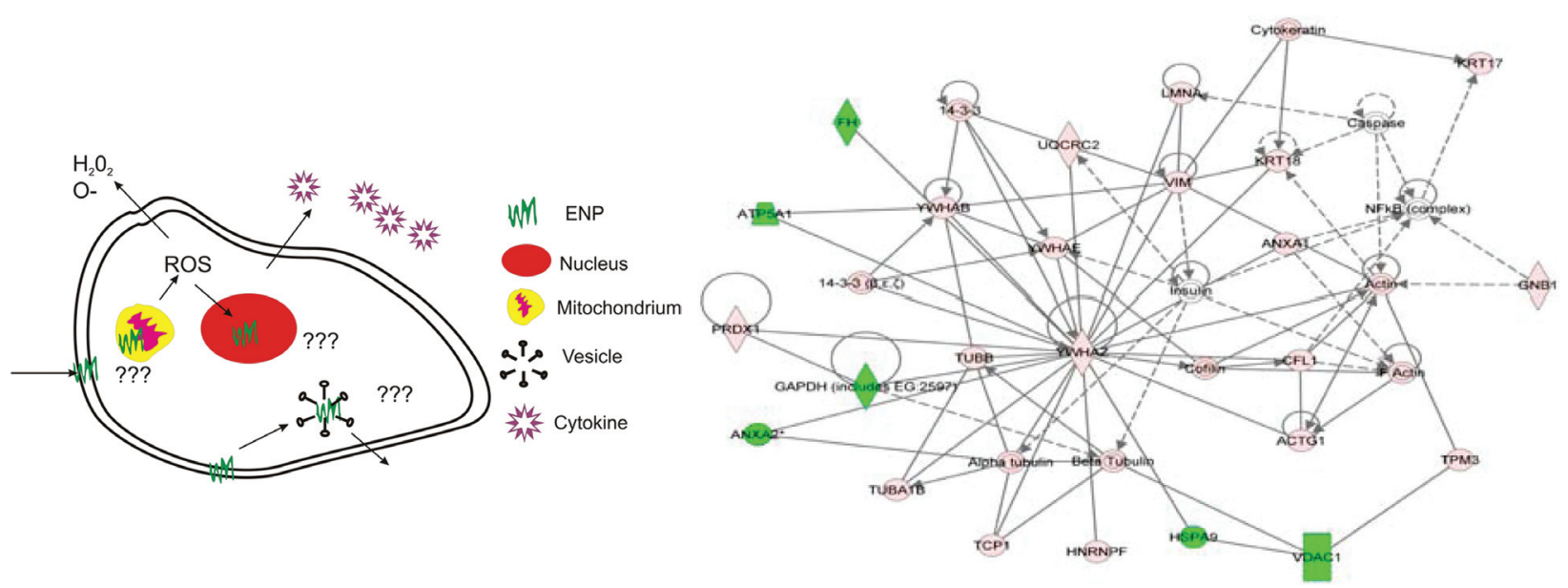

Figure 4 Left: Critical aspects of intracellular signalling: mechanisms of nanoparticle (ENP) entry, ROS induction, nuclear damage and ENP fate after cellular reaction (or death). Right: Protein interacting network 1 . This representative network of differentially expressed proteins shows the protein inter-relationships and relevant signalling pathways. Two major sub-networks within the network are centered by NF- $\mathrm{KB}$ and YWHA2. Proteins in pink are up-regulated while proteins in green are down-regulated. Solid lines represent direct relationships. Dotted lines represent indirect relationships. Lines connecting the proteins indicate known inter-relationships from the IPA database. From [111]. Whether, in this particular case the impacts can be best described as "signalling" or "perturbation of signalling" pathways is open to debate, but the possibility that that signalling may take place at the bio-nano-interface and as such needs to be considered in the design, and interpretation, of nanosafety and nanointeraction studies is one the main messages of the present review. 
with exposure of human bronchial epithelial cells to nanoscale titanium dioxide [111]. Utilizing 2-DE and MS, 46 proteins that were altered at protein expression levels were identified and mapped, using Ingenuity Pathway Analyses $^{\mathrm{TM}}$ (IPA) canonical pathways and Ingenuity Pathway Analyses tox lists, to create protein-interacting networks and proteomic pathways. This provided the first preliminary protein-interacting network maps and may give novel insights into the biological responses and potential toxicity and detoxification pathways of titanium dioxide [111]. However, as with many early studies in an emerging field, there are some concerns regarding how much can be interpreted from this study which lacked appropriate controls [e.g., no bulk $\mathrm{TiO}_{2}$ or other (reference) material has been used for comparison]. Another example of this approach uses proteomic techniques including two-dimensional electrophoresis/ mass spectrometry and protein microarrays to study the differentially expressed proteome and phosphoproteome, respectively [115]. Here, systems biology analysis of the data revealed that unfolded protein-associated endoplasmic reticulum (ER) stress response was the predominant event in response to the presence of gold nanoparticles [115].

An alternative route to inflammation, directly linked to protein conformation and presentation at the bio-nano interface, has recently been suggested by Deng et al. [116]. Their study demonstrated that negatively surface charged nanoparticles can unfold fibrinogen and that the binding of fibrinogen to poly(acrylic acid) coated gold nanoparticles of $5 \mathrm{~nm}$ leads to interaction with the Mac-1 receptor and its activation, leading to a cytokine response through degradation of $\mathrm{I} \kappa \mathrm{B}$, subsequent release of NF- $\kappa \mathrm{B}$ and its translocation to the nucleus. Since plasmatic fibrinogen has been reported to bind many different types of nanomaterials, including the metal oxides $\mathrm{SiO}_{2}$ and $\mathrm{TiO}_{2}$ [117], the authors proposed that fibrinogen-bound nanoparticles are potentially pro-inflammatory. Note that, as indicated above for oxidative stress, activation of an inflammatory pathway does not necessarily correspond to toxicity, but is rather a defensive reaction and may cause no overt damage if transient, and thus an understanding of the kinetics and duration of the response to nanoparticles is vital.

An elegant approach to assessing nanoparticle impacts has been to look at the effect of citrate-reduced gold and silver nanoparticles on primary cultures of murine adrenal medullary chromaffin cells [118]. Carbon-fiber microelectrode amperometry examination of exocytosis in nanoparticle-exposed cells revealed that nanoparticle exposure lead to decreased secretion of chemical messenger molecules, of up to $32.5 \%$ at $48 \mathrm{~h}$ of gold nanoparticle exposure. Repeated stimulation of exocytosis demonstrated that these effects persisted during subsequent stimulations, meaning that nanoparticles do not interfere directly with the vesicle recycling machinery but also that cellular function is unable to recover following vesicle content expulsion [118]. Similar results were also observed in mast cells [118].

Beyond the level of the single cell, the means by which injured cells communicate their distress causing systemic and long-term damage is therefore a critical issue. The adaptive response of nanoparticle-injured cells is an over production of $\mathrm{H}_{2} \mathrm{O}_{2}$ with the consequent generation of free radicals and the secretion of pro-inflammatory cytokines [119]. Recapitulating the systemic effects of nanomaterial toxicity in vitro requires properly scaled in vitro and computational models so that the consequences of localized nanoparticle induced injury to the whole body response can be systematically investigated. Cellcell signalling, and signal propagation across the foetal barrier has recently been shown as the toxicity mechanism by which $\mathrm{CoCr}$ alloy metal nanoparticles induce a novel type of indirect genotoxic effect across cellular barriers $[98,120]$. The CoCr nanoparticles were observed to cause DNA damage and tetraploidy in cells not directly exposed to the nanoparticles [98], i.e., on the other side of the barrier in an in vitro model system, without a significant passage or leakage of metal through the barrier. Such cell-cell signalling is protein mediated, and likely triggered by something present on the nanoparticle surface that interacts with cellular receptors, or induces signalling from lysosomes.

It is a fair criticism of the field to date that the majority of studies published have utilised unrealistically high doses of nanoparticles and that the "toxic effects" that have been reported, and the assays used to detect these effects, lack the sophistication that is needed to fully appreciate potential nanoparticle-induced signalling events. However, this current lack of evidence for nanoparticle-induced signalling impacts is also a consequence of the fact that systems approaches are only beginning to be applied to these issues, and research to address this issue is underway. Data demonstrating nanoparticle induced signalling from nanoparticles located at cell membranes, from nanoparticles taken up into cells, and from nanoparticle-exposed cells to neighbouring cells will soon begin to appear in the literature as this convergence of nanosafety maturing as a discipline and more widespread application of systems biology approaches reaches fruition [Personnal Communications from H. Hofmann (EPFL) and K.A. Dawson (UCD)]. 
Connecting the nature of the bio-nano interface with downstream signalling impacts will be important in teasing out potential longer term consequences of exposure to nanomaterials, and to correlating impacts to the composition of the bio-nano interface and the underlying nanoparticle physico-chemical properties.

\section{The Kinetics concept: Timescales of interaction of nanoparticles with biomolecules and cells}

A deep understanding of the biological effects of nanoparticles requires knowledge of the equilibrium and kinetic binding properties of proteins (and other biomolecules such as lipids and polysaccharides) that associate with the particles, and especially under competitive binding conditions, such as those occurring in vivo [1]. The rates by which different proteins bind to and dissociate from nanoparticles, i.e., the time scales on which particle-associated proteins exchange with free proteins, are critical parameters determining their interaction with receptors, and biological responses generally. The biological outcome may also be different, depending on the relative exchange rates of proteins with nanoparticles and cellular receptors, respectively [3]. In addition, the particle-bound protein may have altered exchange rates with a cellular receptor. It is clear that, in understanding how particles will interact with cells, these issues, currently almost unstudied, are amongst the most fundamental. Additionally, the corona may not immediately reach equilibrium when exposed to a biological fluid, and will evolve as the nanoparticle encounters new milieu, for example, when particles redistribute from one compartment or organ to another, such as upon receptormediated endocytosis from the extracellular environment into the primary endosomal cavity, or from the cytosol to the nucleus [44].

In addition to understanding the kinetics of formation of the corona and its evolution during nanoparticle uptake and translocation, it is vital to understand the fate of both the nanoparticle corona and the nanoparticles themselves in their final sub-cellular locations. In particular, there is emerging evidence that the bio-nano interface can be degraded upon localisation of the nanoparticles in endosomes or lysosomes [113], and indeed even that some nanoparticles themselves, including carbon nanotubes, may degrade in situ in cells or in vivo [121]. Using fluorescently labelled proteins in the nanoparticle corona, it has been possible to track nanoparticle localisation and corona digestion and to correlate this with the toxicity impacts observed [113]. Using amine-modified polystyrene nanoparticles, a detailed event sequence has been tracked showing how nanoparticle location and biological responses are connected - nanoparticles are localised in the lysosomes undergo acid-degradation of the corona, leading to re-expression of the positive charge on the nanoparticles, which were previously masked by the presence of the protein corona, and consequently disruption of the lysosomal wall, leading to a complex set of signalling responses [113]. For aminated dendrimers, a clear generation dependence is observed, reflecting the systematic increase in the number of surface amino groups, implying a similar digestion in the endosomes [79].

The ultimate goal of nanosafety assessment is to be able to correlate the uptake rate, localisation and actual sub-cellular dose with the kinetics of the onset and propagation of the impacts observed. This requires a good understanding of the timing of signalling events that various assays report on, to ensure that experiments are designed with appropriate time-points such that desired effects can be observed. This is especially important for transitory or late-onset impacts, or for impacts that are down-stream of the initial signalling impacts. Cellular responses may not be linear with dose, however, and the process of saturation should be understood. Equally, understanding the intrinsic cellular protection mechanisms through antioxidants is critical to differentiating between responses of different cell types. To fully understand the impacts of different nanomaterials, it is important to identify the relevant cascade pathways and to link the rates of response to the physico-chemical properties of the nanoparticles, to their different bionano interfaces, and to the intrinsic characteristics of the cell-lines. For all processes, the rate of response is the most important characteristic parameter, and relevant rates include:

1. Uptake rates (endocytosis, adhesive interaction) and connection to bio-nano interface composition

2. Impact rates of membrane bound vs. free nanoparticles

3. Signalling rate of nanoparticles attached to cell surface - identification and quantification of most relevant signalling markers at each time point

4. Rate of recovery of relevant signalling markers at each time point

5. Rate of ROS generation

6. Endosomolysis thresholds and rates

7. Rates of trafficking/translocation to other organelles (mitochondria, nuclei) and/or trancytosis 
8. Uptake rates and size thresholds for organelles (mitochondria, nuclei)

9. Identification of impact pathways and rates (including activation/expression of relevant signalling proteins)

10. Identification of types and kinetics of cell-cell signalling impacts

11. Identification of kinetics of evolution [122] and degradation of the bio-nano interface [114] and the underlying nanoparticle degradation both prior to uptake (i.e., in the exposure media and the influence of media composition on nanoparticle degradation rate for example [28]) and following uptake (for example in the lysosomes). As recently suggested by Shannahan et al. [123], the corona may only degrade after lysosomal localisation (of silver nanoparticles) resulting in acid-mediated oxidation and ultimately cell death due to toxic metal ions. Indeed corona degradation in the lysosomes has recently been demonstrated utilising loss of fluorescence signal from fluorescently-labelled serum proteins bound to nanoparticles over time [113]. Thus, elucidating the role of the bio-nano interface in modulating the ionic dissolution of metal and metal-oxide based nanoparticles is of particular importance given the widespread role of these materials in medicine.

Coupled with this is a requirement to understand in detail where nanoparticles are located, in order to correlate impacts with particle localisation. Significant progress to this end has been achieved, and indeed it is now possible to use cellular proteins associated with the different vesicular structures of cellular uptake pathways to report on kinetics of nanoparticle uptake and localisation. Thus, $40 \mathrm{~nm}$ carboxyl-modified polystyrene nanoparticles were shown to first pass through an early endosome intermediate decorated with Rab5, but to rapidly transfer to late endosomes and ultimately lysosomes labelled with Rab9 and Rab7, respectively [90]. Larger nanoparticles of $100 \mathrm{~nm}$ diameter also reach acidic Rab9- and Rab7-positive compartments although at a slower rate compared to the smaller $40 \mathrm{~nm}$ nanoparticles [90]. This information can then be coupled to the kinetics of signalling impacts induced following localisation, and using co-localisation approaches, to qualify particle amounts in the various compartments. Thus, it is possible that upon entering of foreign material, orchestrated defence processes are initiated by the cell, depending on the nature of the nanoparticle corona, and that concentration of nanoparticles, impact time and reaction time would have to be considered as part of a kinetics-based modelling approach.
Alternative routes towards nanoparticle tracking include Raman spectroscopy. The use of Surface Enhanced Raman Scattering from gold nanoparticles and nanoaggregates to probe the environment of the subcellular compartments through which they are trafficked has been demonstrated $[124,125]$. This approach also demonstrated the use of molecular labelled nanoparticles as more specific probes of the local environment [126-128]. However, the uptake rates and mechanisms as well as the subsequent trafficking may be specific to the nanoparticle type, size and surface chemistry. More recently, Raman spectroscopy has been employed to identify and localise unlabelled polystyrene nanoparticles in cells in vitro [129].

\section{What can we learn from viral bio-nano-interfaces and their dynamics?}

Nanoparticles and virus particles share many features, including size range. Independent of their nature, adhesion of particles in the nanometer size range depends mainly on van der Waals forces and not on key-lock concepts as often incorrectly described [130]. Indeed, it has been shown that adhesion processes (which are based on van der Waals and other forces) may lead to phospholipid molecules of the membrane moving apart to let nanoparticles enter into the cell passively [60]. Mathematically, these van der Waals forces can be described considering the work of adhesion, W, geometry, elasticity and forces applied to the system. Almost four decades ago, these forces interacting on the contact points of small particles were described by the JKR (Johnson Kendall Roberts) analysis, $\mathrm{F}=-3 \pi \mathrm{WD} / 8$, where $\mathrm{D}$ is the Hertz contact diameter [131]. The measurement of these forces is possible by applying Atomic Force Microscopy (AFM) [132]. The interparticle forces both for nanoparticles and virus particles are very small and are in the order of thermal diffusion forces. Measurements of self-adhesion forces leading to doublet and triplet formation showed very similar results for polystyrene and virus particles [133]. Proteins can accelerate adhesion between particles/viruses and cells and measurements of this process have revealed a stepwise process, giving evidence of several adhesive states, with significant energy barriers between these states that in fact allow catalytic actions to accelerate the kinetic processes leading to contact.

Theoretical models have moved from trivial and inaccurate lock-and-key-models to the more physically relevant 
van der Waals principles. On the scale of such models, Brownian motion cannot be neglected and thereby adhesion becomes a statistical process leading to a dynamic equilibrium that depends on concentration, thermal energy and the attractive potential. Further research into adhesion and molecular dynamics modelling will allow improved visualization and understanding of the molecular basis of adhesion processes. A recently presented experimental procedure showed that nanoparticles can be functionalized with appropriate ligands to render them membrane-permeant [80]. Recent characterization of the trafficking mechanisms of prion proteins and certain bacteria may present new paradigms for understanding how nanoparticles could enter cells $[60,134]$.

\section{Nanoparticle interactomes: emerging systems biology approaches in nanotoxicology}

Systems biology is an emerging field which seeks to integrate high-throughput biological studies to understand how biological systems function $[135,136]$. By studying the relationships and interactions between various parts of a biological system (e.g., metabolic pathways, organelles, cells, physiological systems, organisms, etc.) it is hoped that eventually an understandable model of the whole system can be developed. One successful approach has been to determine protein interactomes, which are maps or networks connecting a protein to all the other proteins with which it interacts directly or indirectly $[137,138]$. This is possible for proteins, as they must interact with other molecules in order to fulfil their biological roles. For instance, enzymes, receptors, and transcription factors have to bind their substrates, ligands, and target DNA elements, respectively, to execute their function. Thus, removal of one protein will affect the functioning of other proteins, which will in turn affect the functioning of other proteins in a complex network functioning.

Small changes in a protein conformation, such as may be induced by interaction with the surface of a nanoparticle (both engineered and combustion derived) [21], can potentially have large impacts on a protein's function, as well as its interaction with other proteins and in this way affect their function. Thus, introduction of nanoparticles into living systems can affect a whole series of interrelated processes, simply by altering the behaviour of one or two key proteins, which in turn affects the protein-protein interactions. This sort of network type behaviour is referred to as a protein's interactome, and an example of such a connectivity diagram for a nanoparticle-induced toxicity pathway is shown in Figure 4. Thus, a key challenge for the future is to identify the protein networks that are affected by introduction of different nanoparticles, and in this way to determine the nanoparticles' interactome, and connect this to the nature of the nanoparticles' bio-nano interface.

\section{Towards predicting nanoparticle fate and behavior in living organisms based on the bio-nano interface}

If the bio-nano interface is what is actually seen by, and interacts with, organisms, then in principle, mapping and reading a large number of nanoparticle bio-nano interfaces could provide a mechanism for grouping and classification of nanomaterials, and indeed even for predicting nanoparticle fate and behaviour in the future based on the initial bio-nano interface at the point of first contact with a biological system. There is a need for advanced methodologies to study nanoparticles in situ in biofluids, and to understand the packing rules and orientational drivers for specific proteins and other biomolecules to locate at the bio-nano interface, and from this to understand nanoparticle interactomes, or networks of signalling molecules that can be triggered by different bio-nano interfaces.

It is clear that the final cellular location of a nanoparticle will determine the range of cellular pathways and processes that the particle can potentially trigger or disrupt, and thus reaching different intracellular locations leads to different potential functional responses. Once the nanoparticle characteristics can be connected to the nature of the biomolecule layer adsorbed onto the particle, i.e., the bio-nano interface, and the details of the surface exposed peptides or amino acid groups available for interaction with endogenous machinery and other biomolecules, the details of the bio-nano interface can be correlated to the biological responses resulting from the presence of the nanoparticle in vivo.

However, characterising the nature of the nanoparticle corona and the bio-nano-interface is not a trivial task. The recent review by Saptarshi et al. [140] provides a table summarising the approaches that have been utilised in the recent literature to study nanoparticle-protein interactions, with a focus on methods to assess nanoparticle surface driven protein conformational changes and 
uptake of nanoparticles by cellular structures. An earlier review included a more diverse set of approaches, including ones routinely used for assessment of protein-protein interactions, including NMR, phage display libraries, limited proteolysis and many others [141]. An elegant paper by Cukalevski et al. demonstrates that nanoparticle surface charge is a critical parameter for predicting structural changes in adsorbed proteins, as circular dichroism, fluorescence spectroscopy, and limited proteolysis experiments indicated effects on both secondary and tertiary structures, with the effect being specific for each protein studied [21]. Use of advanced imaging approaches such as Raman microscopy can provide important insights regarding the impact of a bio-corona (e.g., using surface-grafted adenosine triphosphate (ATP) as a model of a corona formed in alveolar liquid) on nanoparticle uptake and the fate of the nanoparticles and the protein corona [142]. Raman microscopy unambiguously showed that magnetite nanoparticles are internalized within A549 cells after $24 \mathrm{~h}$ co-incubation, and that the ATP ligand is retained on the nanoparticles throughout the uptake process [142]. Other important approaches include Fluorescence Correlation Microscopy which can be used to study the protein organisation in the corona such as the number of proteins, and whether a monolayer or multi-layer forms and even provides information about the residence time of proteins (although at present limited to single proteins studies) [143], and of course the recent advances in proteomics approaches (e.g., label-free snapshot proteomics) applied to nanoparticles allow quantitative and time-resolved assessments of amount and composition of proteins in nanoparticle coronas [144]. While significant progress is being made, the experimental approaches employed by many studies currently involve detailed study of a single protein with the nanoparticle surface rather than the complete biofluids studies where significant competitive and cooperative binding effects come into play. Additional method development, or optimisation of methods to address and fully characterise dynamic nanoparticle bio-nano-interfaces is required.

Given that it is the nature of the adsorbed protein coating that determines uptake and intracellular trafficking of nanoparticles, in principle, one can begin to think of designing nanoparticles to adsorb specific proteins in order to determine the final cellular location of the nanoparticles. In principle, we should be able to "post" a nanoparticle to anywhere in the cell, simply using the bio-nano interface which will be "read" by the cellular machinery, and direct the nanoparticle to the desired location according to the instructions "printed" on the nanoparticle surface, via the bio-nano interface. By understanding the nature of the bio-nano interface that leads to localisation in specific intracellular locations, versus recycling out of cells, tissues or organs, it may be possible to design nanoparticles that acquire such coatings spontaneously, leading to nanomaterials that are safe by design [145] of their bio-nano interface.

\section{Bio-nano interface based structure- activity relationships?}

Nanoparticle uptake, intracellular trafficking and cellular response mechanisms have been extensively studied in vitro. Although the extent to which results of in vitro models are translatable to in vivo exposures is debateable, such models potentially provide a basis for rapid screening of potential toxicants or nanobased medical treatments and also provide an insight into cellular interactions of nanoparticles. Furthermore, Directive 2010/6386/609/EU on the protection of animals used for experimental and other scientific purposes indicates that the EU Commission and the member states should actively support the development, validation and acceptance of methods which could reduce, refine or replace the use of laboratory animals (3Rs). However, given the myriad of nanoparticle types, each potentially with variable chemical functionalisations and sizes, and each of which can present a different bio-nano interface depending on the exposure conditions (media $\mathrm{pH}$, ionic strength, biomolecule composition, etc.), and given the similarly huge number of cell types and lines, purported to represent target organs in vivo, the route towards Quantitative Structure Activity Relationships (QSARs) is not clear. In toxicology, responses are commonly classified in terms of effective concentrations which elicit an endpoint of an in vitro or in vivo assay, but, for a given nanoparticle, significant variations can be seen between different assays and cell lines. It is therefore important to identify critical points and rates of interaction between nanomaterials and biological signalling pathways, most notably via the bio-nano interface, and identify routes towards establishing quantifiable parameters governing the activity of nanoparticles and their structural dependences. A novel biological surface adsorption index (BSAI) for nanoparticles that was proposed for use to predict the "biological identity" of nanoparticles (see Figure 5) could serve as a useful descriptor in modelling of nanoparticle structureactivity relationships [139]. Notably, consideration should be given to both acute and chronic effects, and indeed to the potential for novel other end-points (not yet identified 


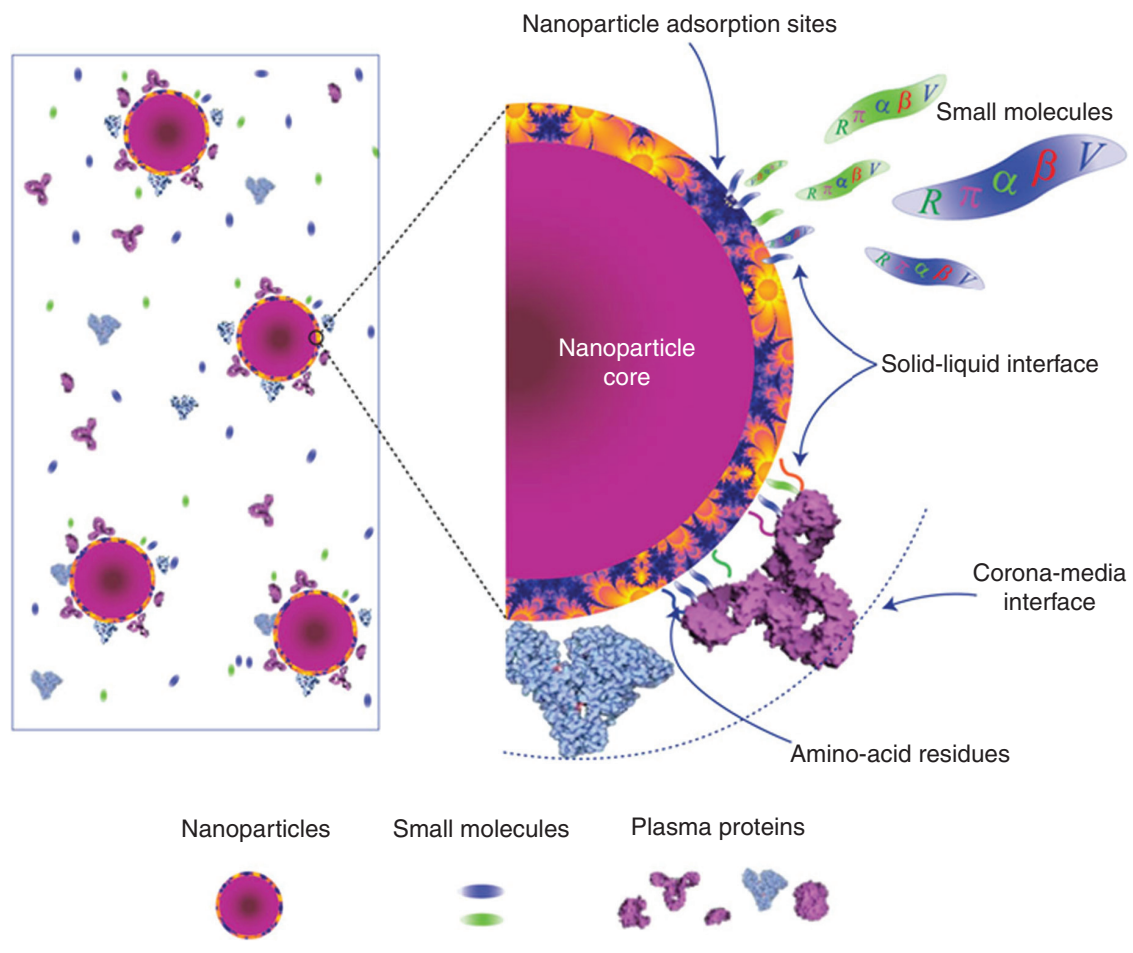

Figure 5 Illustration of the competitive adsorption of small molecules and proteins onto the surface adsorption sites of nanoparticles. Left: in a physiological environment, nanoparticles are exposed to different proteins and small molecules. Right: the competitive adsorption of small molecules (upper) and the amino-acid residues of proteins (lower) on a nanoparticle. The orange ring on the nanoparticle with blue irregular shapes represents the adsorption sites that are not uniformly distributed on the nanoparticle surface. Small molecules with known molecular descriptors $[R, \pi, \alpha, \beta, V]$ can be used as probes to measure the molecular interaction strengths of the nanoparticles with small molecules and biomolecules. From reference [139]. Note that the particles, small molecules and proteins are not drawn to scale.

within the scope of $\mathrm{OECD}^{2}$ or other approaches), such as the influence of nanoparticles on protein fibrillation in situ, and the frustrated phagocytosis caused by high aspect ratio nanomaterials such, as carbon nanotubes, identified in the SCENIHR Opinion on Risk Assessment of Products of Nanotechnologies [146]. Indeed, it is worth reiterating that even now there is no simple toxicity assay or combination of assays that could predict mesothelioma, the asbestos-induced cancer [147].

\section{Conclusions and recommendations for researchers}

This review paper has described some of the key research towards understanding the role of the layer of adsorbed biomolecules (the biomolecule corona) on the fate and behaviour of nanoparticles upon contact with living systems. We have focussed the existing data and knowledge around four key concepts to demonstrate the central role of

2 Organisation for Economic Cooperation and Development. the bio-nano interface for understanding, and eventually predicting, nanoparticle interactions, impact and safety. These four concepts are: Coating, Translocation, Signalling and Kinetics. As demonstrated by the degree of cross-referencing between the concepts, each is closely linked with the others and can only be fully understood in light of the others. Based on the above discussions, a number of key recommendations for researchers have been drawn, to help in the framing of future experimental approaches, as follows:

1. Recognise that nanoparticles cannot be treated (regulated) as non-interacting species, but rather must be thought of, and studied as, biological entities, which interact with proteins and other molecules in the (micro)environment and are influenced by this biomolecule interface in all their subsequent interactions with organs, tissues cells, intracellular organelles. Thus, the key parameter to understand nanoparticle interactions with living systems and their biological impacts, becomes the nature, composition, organisation and structure, and evolution of the bionano interface [42], which is a consequence of their physico-chemical parameters and the nature of the biological microenvironment [54]. 
In its simplest manifestation, this then suggests that studies of nanoparticle interactions with living systems should include as standard characterisation of the nanomaterials size, size distribution, surface charge as a minimum in the dispersion medium in which they will be exposed to the test species. Some visualisation of the agglomeration state should also be included where possible, such as Electron Microscopy imaging coupled with, for example, Differential Centrifugation Sedimentation, which reports on the distribution of particle monomers, dimers, trimers and larger aggregates in complex biofluids [5]. Research Infrastructures such as FP7-QualityNano (www.qualitynano.eu) are an important mechanism to provide access to such methodologies to the nanosafety research community.

A more advanced manifestation of this requires the development of new tools and approaches to characterise the bio-nano interface in detail, including mapping the outermost peptide sequences of the proteins contained in the nanoparticle-corona, as it is these amino acid sequences that will be available to engage with biological machinery. Depending on the orientation of proteins in the corona, and their degree of unfolding, new or so-called "cryptic" presentations of amino acids could result from protein binding to nanoparticles, resulting in the potential for new protein-protein interactions and/or altered signalling [140, 141, 148].

2. Recognise the central role of the bio-nano interface as the determinator of nanoparticle fate and behaviour in the environment and in humans, and frame studies in a manner that connects uptake and impacts to bionano interface and its signalling interactome, i.e., the full set of other biomolecules that interact with the biomolecules at the bio-nano interface and the signalling implications of these.

This also requires a reassessment of how we design in vitro experiments to be representative of in vivo conditions, and to allow in vitro-in vivo correlations, taking account of the fact that quite different bio-nano interfaces can result from different mass transport, kinetic and concentration regimes. Thus, the $3-10 \%$ serum and stationary (steady-state) conditions typical of in vitro experiments may not be fully suitable to predict the bio-nano interface and the consequent impacts from the same nanomaterials subject to interstitial or vascular flow rates and protein concentrations typical in vivo (55-80\% protein).

3. Consider a framework for classification of nanomaterials based on the details of their bio-nano interface and its stability, evolution and degradation rather than one based solely on underlying physicochemical properties. In this way, direct connections can be made with potential for bioaccumulation, potential for degradation, and other more direct toxicities in addition to allowing more subtle effects from perturbed signalling pathways to emerge. It will also enable issues such as opsonisation and immunogenicity, and the potential for nanomaterials to modulate protein fibrillation to be addressed as part of the assessment process. Important steps here will include a detailed understanding of the conditions under which nanoparticle exocytosis may occur, and how signals for exocytosis could be "designed" into the bio-nano interface, in first steps towards safety by design.

Acknowledgements: This paper is based on inputs collected for the nano-bio interactions chapter of the European Nanosafety Cluster Strategic Research Agenda (coordinated by Prof. Kai Savolainen, Finnish Institute of Occupational Health, Helsinki). IL acknowledges the stimulating discussions with her former colleagues at the Centre for BioNano Interactions at University College Dublin. Funding from the QualityNano project http:// www.qualitynano.eu, financed by the European Community Research Infrastructures under the FP7 Capacities Programme (Grant No. INFRA-2010-262163), is gratefully acknowledged (IL). ACG received support from the Fonds National de la Recherche (FNR) of Luxembourg within the project NanEAU II (FNR/10/SR/825684). DB is funded by the EU grants PRD College (GA 223581), NanoTOES (GA 264506), and HUMUNITY (GA 316383), and by a grant of The Fondazione Cariplo 2011-2014. BF is funded, in part, by the Swedish Research Council for Environment, Agricultural Sciences and Spatial Planning (FORMAS), and the FP7 grant NANOSOLUTIONS (GA 309329). AA acknowledges funding from: FP7 InLiveTox (228625), ReLiver (304961) and the Italian Ministry of Education, University \& Research (MIUR) (Project PRIN 2010, MIND).

Received May 30, 2013; accepted October 29, 2013

\section{References}

1. Lynch I, Cedervall T, Lundqvist M, Cabaleiro-Lago C, Linse S, Dawson KA. The nanoparticle-protein complex as a biological entity; a complex fluids and surface science challenge for the 21st century. Adv Colloid Interface Sci 2007;134-135:167-74. 
2. Cedervall T, Lynch I, Lindman S, Nilsson $H$, Thulin E, Linse S, et al. Understanding the nanoparticle-protein corona using methods to quantify exchange rates and affinities of proteins for nanoparticles. Proc Nat Acad Sci 2007a;104:2050-5.

3. Walczyk D, Baldelli-Bombelli F, Campbell A, Lynch I, Dawson KA. What the Cell "Sees" in Bionanoscience. JACS 2010;132:5761-8.

4. Stark WJ. Nanoparticles in Biological Systems. Angewandte Chemie International Edition 2011;50:1242-58.

5. Dawson KA, Anguissola S, Lynch I. The need for in situ characterisation in nanosafety assessment: funded transnational access via the QNano research infrastructure. Nanotoxicology 2013;7:346-9.

6. Schürch S, Gehr P, Im Hof V, Geiser M, Green F. Surfactant displaces particles toward the epithelium in airways and alveoli. Respir Physiol 1990;80:17-32.

7. Kendall M, Hutton BM, Tetley TD, Nieuwenhuijsen M, Wigzell E, Jones $F$. Investigation of fine atmospheric particle surfaces and lung lining fluid interactions using XPS. Appl Surf Sci 2001;178:27-36.

8. Kendall M, Tetley TD, Wigzell E, Hutton B, Nieuwenhuijsen M, Luckham P. Lung lining liquid modifies PM2.5 in favour of particle aggregation: A protective mechanism. Am J Physiol: Lung 2002;282:L109-14.

9. Kendall M, Guntern J, Lockyer NP, Jones FH, Hutton BM, Lippmann M, et al. Urban PM2.5 surface chemistry and interactions with broncho-alveolar lavage fluid (BALF). J Inhal Tox 2004;16 (suppl. 1):115-29.

10. Kendall M, Brown L, Trought K. Molecular adsorption at particle surfaces: A PM toxicity mediation mechanism. J Inhal Tox 2004;16 (suppl. 1):99-105.

11. Kendall M, Holgate S. Exposure, dose, translocation and impacts of engineered nanomaterials in humans. Respirology 2012;17:743-58.

12. Kendall M. Fine airborne urban particles (PM2.5) sequester lung surfactant and amino acids from human lung lavage. Am J Physiol Lung Cell Mol Physiol 2007;293:L1053-8.

13. Meerasa A, Huang JG, Gu FX. Human serum lipoproteins influence protein deposition patterns on nanoparticle surfaces. ACS Appl Mater Interfaces 2013;5:489-93.

14. Yang S, Bar-Ilan O, Peterson RE, Heideman W, Hamers RJ, Pedersen JA. Influence of humic Acid on titanium dioxide nanoparticle toxicity to developing zebrafish. Environ Sci Technol 2013;47:4718-25.

15. Gasser M, Rothen-Rutishauser B, Krug HF, Gehr P, Nelle M, Yan B, et al. The adsorption of biomolecules to multi-walled carbon nanotubes is influenced by both pulmonary surfactant lipids and surface chemistry. J Nanobiotechnology 2010;8:31.

16. Park H, Grassian VH. Commercially manufactured engineered nanomaterials for environmental and health studies: Important. insights provided by independent characterization. Environ Toxicol Chem 2010;29:715-21.

17. Quik JT, Lynch I, Van Hoecke K, Miermans CJ, De Schamphelaere KA, Janssen $C R$, et al. Effect of natural organic matter on cerium dioxide nanoparticles settling in model fresh water. Chemosphere 2010;81:711-5.

18. Baalousha M, Manciulea A, Cumberland S, Kendall K, Lead JR. Aggregation and surface properties of iron oxide nanoparticles: influence of $\mathrm{pH}$ and natural organic matter. Environ Toxicol Chem 2008;27:1875-82.
19. Pelley AJ, Tufenkji N. Effect of particle size and natural organic matter on the migration of nano- and microscale latex particles in saturated porous media. J Colloid Interf Sci 2008;321:74-83.

20. OECD, Series on the Safety of Manufactured Nanomaterials, No. 27, List of manufactured nanomaterials and list of endpoints for phase one testing of the sponsorship programme for the testing of manufactured nanomaterials: revision. ENV/JM/ MONO(2010)46 2010.

21. Cukalevski R, Lundqvist M, Oslakovic C, Dahlback B, Linse S, Cedervall T. Structural changes in apolipoproteins bound to nanoparticles. Langmuir 2011;27:14360-9.

22. Bailes J, Gazi S, Ivanova R, Soloviev M. Effect of gold nanoparticle conjugation on the activity and stability of functional proteins. Methods Mol Biol 2012;906:89-99.

23. Lesniak A, Fenaroli F, Monopoli MP, Aberg C, Dawson KA, Salvati A. Effects of the presence or absence of a protein corona on silica nanoparticle uptake and impact on cells. ACS Nano 2012;6:5845-57.

24. Lesniak A, Campbell A, Monopoli MP, Lynch I, Salvati A, Dawson KA. Serum heat inactivation affects protein corona composition and nanoparticle uptake. Biomaterials 2010;31:9511-8.

25. Maiorano G, Sabella S, Sorce B, Brunetti V, Malvindi MA, Cingolani $R$, et al. Effects of cell culture media on the dynamic formation of protein-nanoparticle complexes and influence on the cellular response. ACS Nano 2010;4:7481-91.

26. Linse S, Cabaleiro-Lago C, Xue W-F, Lynch I, Lindman S, Thulin E, et al. Nucleation of protein fibrillation by nanoparticles. PNAS 2007;104:8691-6.

27. Wang Y, Li Y, Costanza J, Abriola LM, Pennell KD. Enhanced mobility of fullerene (C60) nanoparticles in the presence of stabilizing agents. Environ Sci Technol 2012;46:11761-9.

28. Mahon E, Hristov DR, Dawson KA. Stabilising fluorescent silica nanoparticles against dissolution effects for biological studies. Chem Commun (Camb) 2012;48:7970-2.

29. Ge C, Du J, Zhao L, Wang L, Liu Y, Li D, et al. Binding of blood proteins to carbon nanotubes reduces cytotoxicity. Proc Natl Acad Sci USA 2011;108:16968-73.

30. Monopoli MP, Dorota Walczyk D, Lowry-Campbell A, Elia E, Lynch I, Bombelli FB, et al. Physical-chemical aspects of protein corona: relevance to in vitro and in vivo biological impacts of nanoparticles. J Am Chem Soc 2011;133:2525-34.

31. Casey A, Herzog E, Lyng FM, Byrne HJ, Chambers G, Davoren M. SWCNT suppress inflammatory mediator responses in human lung epithelium in vitro. Toxicol Lett 2008;179: 78-84.

32. Salvati A, Pitek AS, Monopoli MP, Prapainop K, Bombelli FB, Hristov DR, et al. Transferrin-functionalized nanoparticles lose their targeting capabilities when a biomolecule corona adsorbs on the surface. Nat Nanotechnol 2013;8:137-43.

33. Damiano MG, Mutharasan RK, Tripathy S, McMahon KM, Thaxton CS. Templated high density lipoprotein nanoparticles as potential therapies and for molecular delivery. Adv Drug Deliv Rev 2012;65:649-62.

34. Lesniak A, Salvati A, Santos-Martinez MJ, Radomski MW, Dawson KA, Åberg C. Nanoparticle adhesion to the cell membrane and its effect on nanoparticle uptake efficiency. J Am Chem Soc 2013;135:1438-44. 
35. Shvedova AA, Kagan VE, Fadeel B. Close encounters of the small kind: adverse effects of man-made materials interfacing with the nano-cosmos of biological systems. Annu Rev Pharmacol Toxicol 2010;50:63-88.

36. Klein J. Probing the interactions of proteins and nanoparticles. Proc Natl Acad Sci USA 2007;104:2029-30.

37. Deng ZJ, Liang M, Toth I, Monteiro MJ, Minchin RF. Molecular interaction of poly(acrylic acid) gold nanoparticles with human fibrinogen. ACS Nano 2012;6:8962-9.

38. Cedervall T, Lynch I, Foy M, Berggård T, Donnelly SC, Cagney G, et al. Detailed Identification of Plasma Proteins Adsorbed on Copolymer Nanoparticles. Angew Chem Int Ed 2007;46:5754-6.

39. Krug HF, Wick P. Nanotoxicology: an interdisciplinary challenge. Angewandte Chemie Internat Ed 2011;50:1260-78.

40. Rivera Gil P, Oberdörster G, Elder A, Puntes V, Parak WJ. Correlating physico-chemical with toxicological properties of nanoparticles: the present and the future. ACS Nano 2010;4:5527-31.

41. Kendall M, Ding P, Kendall K. Particle and nanoparticle interactions with fibrinogen: the importance of aggregation in nanotoxicology. Nanotoxicology 2011;5:55-65.

42. Fadeel B, Feliu N, Vogt C, Abdelmonem AM, Parak WJ. Bridge over troubled waters: understanding the synthetic.. and biological identities of engineered nanomaterials. Wiley Interdiscip Rev Nanomed Nanobiotechnol 2013;5: 111-29.

43. Savolainen KB, Brouwer D, Fadeel B, Fernandes T, Kuhlbusch T, Landsiedel R, et al. Nanosafety in Europe 2015-2025: Towards safe and sustainable nanomaterials and nanotechnology innovations. FIOH: Finland, 2013.

44. Lundqvist $M$, Stigler J, Cedervall T, Berggård T, Flanagan $M$, Lynch I, et al. The evolution of the protein corona around nanoparticles: a test study. ACS Nano 2011;5:7503-9.

45. Lacerda SH, Park J, Meuse C, Pristinski D, Becker ML, Karim A, et al. Interaction of gold nanoparticles with common human blood proteins. ACS Nano 2009;4:365-79.

46. Schulze C, Schaefer UF, Ruge CA, Wohlleben W, Lehr C-M. Interaction of metal oxide nanoparticles with lung surfactant protein A. EJPB 2010;77:376-83.

47. Kendall M, Ding P, Mackay R-M, Madsen J, Deb R, MacKenzie Z, et al. Surfactant protein D alters cellular uptake of particles and nanoparticles. Nanotoxicology 2013;7:963-73.

48. Fleischer CC, Kumar U, Payne CK. Cellular binding of.. anionic nanoparticles is inhibited by serum proteins independent of nanoparticle composition. Biomater Sci 2013;1:975-982.

49. Lundqvist M, Stigler J, Cedervall T, Elia G, Lynch I, Dawson K. Nanoparticle size and surface properties determine the protein corona with possible implications for biological impacts. PNAS 2008;105:14265-70.

50. Schäffler M, Semmler-Behnke M, Sarioglu H, Takenaka S, Wenk A, Schleh C, et al. Serum protein identification and quantification of the corona of 5, 15 and $80 \mathrm{~nm}$ gold nanoparticles. Nanotechnology 2013;24:265103.

51. Jedlovszky-Hajdú A, Bombelli FB, Monopoli MP, Tombácz E, Dawson KA. Surface coatings shape the protein corona of. SPIONs with relevance to their application in vivo. Langmuir 2012;28:14983-91.
52. Amiri H, Bordonali L, Lascialfari A, Wan S, Monopoli MP, Lynch I, et al. Protein corona affects the relaxivity and MRI contrast efficiency of magnetic nanoparticles. Nanoscale 2013;5:8656-65.

53. Walkey CD, Chan WC. Understanding and controlling the interaction of nanomaterials with proteins in a physiological environment. Chem Soc Rev 2012;41:2780-99.

54. Yang ST, Liu Y, Wang YW, Cao A. Biosafety and bioapplication of. nanomaterials by designing protein-nanoparticle interactions. Small 2013;9:1635-53.

55. Hyung H, Fortner JD, Hughes JB, Kim JH. Natural organic matter stabilizes carbon nanotubes in the aqueous phase. Environ Sci Technol 2007;41:179-84.

56. French RA, Jacobson AR, Kim B, Isley SL, Penn RL, Baveye PC. Influence of ionic strength, $\mathrm{pH}$, and cation valence on aggregation kinetics of titanium dioxide nanoparticles. Environ Sci Technol 2009;43:1354-9.

57. Von Wandruszka R. The secondary structure of humic acid and its environmental implications. Washington, D.C.: US EPA, 1998.

58. Ogawara KF, Nagayama S, Minato K, Higaki K, Kai T, Kimura T. Pre-coating with serum albumin reduces receptor-mediated. hepatic disposition of polystyrene nanosphere: implications for rational design of nanoparticles. J Control Release 2004;100:451-5.

59. Lunov O, Syrovets T, Loos C, Beil J, Delacher M, Tron K, et al. Differential uptake of functionalized polystyrene nanoparticles by human macrophages and a monocytic cell line. ACS Nano 2011;5:1657-69.

60. Geiser M, Rothen-Rutishauser BM, Kapp N, Schürch S, Kreyling W, Schulz H, et al. Ultrafine particles cross cellular membranes by non-phagocytic mechanisms in lungs and in cultured cells. Environ Health Perspect 2005;113:1555-60.

61. Rothen-Rutishauser BM, Kiama SG, Gehr P. A three-dimensional cellular model of the human respiratory tract to study the interaction with particles. Amer J Respir Cell Molec Biol 2005;32:281-9.

62. Blank F, Gehr P, Rothen-Rutishauser B. Dendritic cells and macrophages form a transepithelial network against. foreign particulate antigens. Amer J Respir Cell Molec Biol 2007;36:669-77.

63. Blank F, Rothen-Rutishauser B, Schürch S, Gehr P. An optimized. in vitro model of the respiratory tract wall to study particle cell. interactions. J Aerosol Med 2006;19:392-405.

64. Kreyling WG, Semmler M, Erbe F, Mayer S, Takenaka S, Schultz J. Translocation of ultrafine insoluble iridium particles from lung epithelium to extrapulmonary organs is size dependent but very low. Toxicol Env Health Part A 2002;65:1513-30.

65. Kreyling WG, Semmler-Behnke M, Seitz J, Scymczak W, Wenk A, Mayer $P$, et al. Size dependence of the translocation of inhaled iridium and carbon nanoparticle aggregates from the lung of rats to the blood and secondary target organs. Inhal Toxicol 2009;21(S1):55-60.

66. Gehr P, Green FH, Geiser M, Im Hof V, Lee MM, Schürch S. Airway surfactant, a primary defense barrier: mechanical and immunological aspects. J Aerosol Med 1996;9:163-81.

67. Ruge CA, Schaefer UF, Herrmann J, Kirch J, Cañadas O, Echaide $M$, et al. The interplay of lung surfactant proteins and lipids assimilates the macrophage clearance of nanoparticles. PLoS ONE 2012;7:e40775.

68. Hirn S, Semmler-Behnke M, Schleh C, Wenk A, Lipka J, Schäffler M, et al. Particle size-dependent and surface charge- 
dependent biodistribution of gold nanoparticles after intravenous administration. Eur J Pharm Biopharm 2011;77:407-16.

69. Kunzmann A, Andersson B, Thurnherr T, Krug HF, Scheynius A, Fadeel $B$. Toxicology of engineered nanomaterials: Focus on biocompatibility, biodistribution and biodegradation. Biochim Biophys Acta 2011;1810:361-73.

70. Kunzmann A, Andersson B, Vogt C, Feliu N, Ye F, Gabrielsson S, et al. Efficient internalization of silica-coated iron oxide nanoparticles of different sizes by primary human macrophages and dendritic cells. Toxicol Appl Pharmacol 2011;253:81-93.

71. Konczol M, Ebeling S, Goldenberg E, Treude F, Gminski R, Giere R, et al. Cytotoxicity and genotoxicity of sizefractionated iron oxide (magnetite) in A549 human lung epithelial cells: role of ROS, JNK, and NF-kappaB. Chem Res Toxicol 2011;24:1460-75.

72. Gao J, Xu B. Applications of nanomaterials inside cells. Nano Today 2009;4:37-51.

73. Treuel L, Xiue Jiang X, Nienhaus GU. New views on cellular uptake and trafficking of manufactured nanoparticles. J $R$ Soc Interface 2013;10:20120939.

74. Limbach LK, Wick P, Manser P, Grass RN, Bruinink A, Stark WJ. Exposure of engineered nanoparticles to human. lung epithelial cells: influence of chemical composition and. catalytic activity on oxidative stress. Environ Sci Technol 2007;41:4158-63.

75. Shapero K, Fenaroli F, Lynch I, Cottell DC, Salvati A, Dawson KA. Time and space resolved uptake study of silica nanoparticles by. human cells. Mol Biosyst 2011;7:371-8.

76. Salvati AA, dos Santos T, Varela J, Pinto P, Lynch I, Dawson KA. Experimental and theoretical approach to comparative nanoparticle and small molecule intracellular import, translocation, and export. NanoMedicine 2011;7:818-26.

77. Higuchi Y, Wu C, Chang KL, Irie K, Kawakami S, Yamashita F, et al. Polyamidoamine dendrimer-conjugated quantum dots for efficient labeling of primary cultured mesenchymal stem cells. Biomaterials 2011;32:6676-82.

78. Han M, Kickhoefer VA, Nemerow GR, Rome LH. Targeted vault. nanoparticles engineered with an endosomolytic peptide deliver. biomolecules to the cytoplasm. ACS Nano 2011;5:6128-37.

79. Mukherjee SP, Lyng FM, Garcia A, Davoren M, Byrne HJ. Mechanistic studies of in vitro cytotoxicity of Poly(amidoamine) dendrimers in mammalian cells. Toxicol Appl Pharm 2010;248:259-68.

80. Wang T, Bai J, Jiang X, Nienhaus U. Cellular uptake of. nanoparticles by membrane penetration: a study combining confocal microscopy with FTIR spectroelectrochemistry. ACS Nano 2012;6:1251-9.

81. Brandenberger C, Müller C, Ali Z, Lenz A-G, Schid O, Parak WJ, et al. Quantitative evaluation of cellular uptake and trafficking of plain and polyethylene glycol-coated gold nanoparticles. Small 2010;6:1669-78.

82. dos Santos T, Varela J, Lynch I, Salvati A, Dawson KA. Effects of transport inhibitors on the cellular uptake of carboxylated polystyrene nanoparticles in different cell lines. PLoS One 2011;6:e24438.

83. Ehrenberg MS, Friedman AE, Finkelstein JN, Oberdörster G, McGrath JL. The influence of protein adsorption on nanoparticle association with cultured endothelial cells. Biomaterials 2009;30:603-10.

84. Kreuter J, Shamenkov D, Petrov V, Ramge P, Cychutek K, Koch-Brandt C, et al. Apolipoprotein-mediated transport of nanoparticle-bound drugs across the blood-brain barrier. J Drug Target 2002;10:317-25.

85. Kreuter J. Influence of the surface properties on nanoparticlemediated transport of drugs to the brain. J Nanosci Nanotechnol 2004;4:484-8.

86. Zaki NM, Tirelli N. Gateways for the intracellular access of. nanocarriers: a review of receptor-mediated endocytosis mechanisms and of strategies in receptor targeting. Expert Opin Drug Deliv 2010;7:895-913.

87. Hillaireau H, Couvreur P. Nanocarriers' entry into the cell: relevance to drug delivery. Cell Mol Life Sci 2009;66:2873-96.

88. Lin A, Sabnis A, Kona S, Nattama S, Patel H, Dong JF, et al. Shear-regulated uptake of nanoparticles by endothelial cells and development of endothelial-targeting nanoparticles. J Biomed Mater Res A 2010;93:833-42.

89. Vincent A, Babu S, Heckert E, Dowding J, Hirst SM, Inerbaev TM, et al. Protonated nanoparticle surface governing ligand tethering and cellular targeting. ACS Nano 2009;3:1203-11.

90. Sandin P, Fitzpatrick LW, Simpson JC, Dawson KA. High-speed. imaging of rab family small gtpases reveals rare events in nanoparticle trafficking in living cells. ACS Nano 2012;6: 1513-21.

91. Jin H, Heller DA, Strano MS. Single-particle tracking of endocytosis and exocytosis of single-walled carbon nanotubes in NIH-3T3 cells. Nano Lett 2008;8:1577-85.

92. Chithrani BD, Chan WC. Elucidating the mechanism of cellular uptake and removal of protein-coated gold nanoparticles of. different sizes and shapes. Nano Lett 2007;7:1542-50.

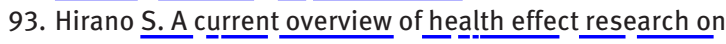
nanoparticles. Environ Health Prev Med 2009;14:223-5.

94. Schins RP, Knaapen AM. Genotoxicity of poorly soluble particles. Inhal Toxicol 2007;19(Suppl 1):189-98.

95. Chan JK, Vogel CF, Baek J, Kodani SD, Uppal RS, Bein KJ, et al. Combustion derived ultrafine particles induce cytochrome P450 expression in specific lung compartments in the developing neonatal and adult rat. Am J Physiol Lung Cell Mol Physiol 2013;304:L665-77.

96. Park KH, Chhowalla M, Iqbal Z, Sesti F. Single-walled carbon nanotubes are a new class of ion channel blockers. J Biol Chem 2003; $278: 50212-6$.

97. Vranic S, Boggetto N, Contremoulins V, Mornet S, Reinhardt $\mathrm{N}$, Marano F, et al. Deciphering the mechanisms of cellular uptake of engineered nanoparticles by accurate evaluation of internalization using imaging flow cytometry. Part Fibre Toxicol 2013;10:2.

98. Bhabra G, Sood A, Fisher B, Cartwright L, Saunders M, Evans WH, et al. Nanoparticles can cause DNA damage across a cellular barrier. Nat Nanotechnol 2009;4:876-83.

99. Sood A, Salih S, Roh D, Lacharme-Lora L, Parry M, Hardiman B, et al. Signalling of DNA damage and cytokines across cell barriers exposed to nanoparticles depends on barrier thickness. Nat Nanotechnol 2011;6:824-33.

100. Weyand B, von Schroeder HP. Altered VEGF-A and receptor mRNA expression profiles, and identification of VEGF144 in foetal rat calvaria cells, in coculture with microvascular endothelial cells. Cell Biol Int 2013;37:713-24.

101. Nic Ragnaill M, Bramini M, Ye D, Couraud PO, Romero IA, Weksler B, et al. Paracrine signalling of inflammatory cytokines from an in vitro Blood Brain Barrier upon exposure to polymeric nanoparticles. Analyst. 2013 Nov 5. [Epub ahead of print]. 
102. Oberdörster G, Oberdörster E, Oberdörster J. Nanotoxicology: an emerging discipline evolving from studies of ultrafine particles. Environ Health Perspect 2005;113:823-39.

103. McKim JM. Building a tiered approach to in vitro predictive toxicity screening: a focus on assays with in vivo relevance. Comb Chem High Throughput Screen 2010;13:188-206.

104. Lavelle C, Berry H, Beslon G, Ginelli F, Giavitto J-L, Kapoula Z, et al. From molecules to organisms: towards multiscale integrated models of biological systems. Theoretical Biology Insights 2008;1:13-22.

105. Bassingthwaighte JB, Chizeck HJ, Atlas LE. Strategies and. tactics in multiscale modeling of cell-to-organ systems. Proc IEEE Inst Electr Electron Eng 2006;94:819-30.

106. Díaz-Zuccarini V, Lawford PV. An in-silico future for the engineering of functional tissues and organs. Organogenesis 2010;6:245-51.

107. Xia T, Kovochich M, Brant J, Hotze M, Sempf J, Oberley T, et al. Comparison of the abilities of ambient and manufactured nanoparticles to induce cellular toxicity according to an oxidative stress paradigm. Nano Lett 2006;6:1794-807.

108. Shvedova AA, Pietroiusti A, Fadeel B, Kagan VE. Mechanisms of carbon nanotube-induced toxicity: focus on oxidative stress. Toxicol Appl Pharmacol 2012;261:121-33.

109. Mailloux RJ, Bériault R, Lemire J, Singh R, Chénier DR, Hamel RD, et al. The tricarboxylic acid cycle, an ancient metabolic network with a novel twist. PLoS One 2007;1:e690.

110. Ahamed M, Akhtar MJ, Siddiqui MA, Ahmad J, Musarrat J, Al-Khedhairy AA, et al. Oxidative stress mediated apoptosis induced by nickel ferrite nanoparticles in cultured A549 cells. Toxicology 2011;283:101-8.

111. Ge Y, Bruno M, Wallace K, Winnik W, Prasad RY. Proteome profiling reveals potential toxicity and detoxification pathways following exposure of BEAS-2B cells to engineered nanoparticle titanium dioxide. Proteomics 2011;11:2406-22.

112. Bexiga MG, Varela JA, Wang F, Fenaroli F, Salvati A, Lynch I, et al. Cationic nanoparticles induce caspase 3 and 7-mediated cytotoxicity in a human astrocytoma cell line. Nanotoxicology 2011;5:557-67.

113. Wang F, Yu L, Salvati A, Dawson KA. The biomolecular corona is retained during nanoparticle uptake and protects the cells from the damage induced by cationic nanoparticles until degraded in the lysosomes. Nanomedicine 2013;S1549-9634:00182-2.

114. Mukherjee SP, Byrne HJ. Polyamidoamine dendrimer nanoparticle cytotoxicity, oxidative stress, caspase activation and infammatory response: experimental observation and numerical simulation. Nanomedicine: Nanotechnology, Biology, and Medicine 2013;9:202-11.

115. Tsai YY, Huang YH, Chao YL, Hu KY, Chin LT, Chou SH, et al. Identification of the nanogold particle-induced endoplasmic reticulum stress by omic techniques and systems biology analysis. ACS Nano 2011;5:9354-69.

116. Deng ZJ, Mingtao Liang M, Monteiro M, Toth I, Minchin RF. Nanoparticle-induced unfolding of fibrinogen promotes Mac-1 (CD11b/CD18) receptor activation and pro-inflammatory cytokine release. Nat Nanotechnol 2010;6:39-44.

117. Deng ZJ, Mortimer G, Schiller T, Musumeci A, Martin D, Minchin RF. Differential plasma protein binding to metal oxide nanoparticles. Nanotechnology 2009;20:455101.

118. Love SA, Haynes CL. Assessment of functional changes in nanoparticle-exposed neuroendocrine cells with. amperometry: exploring the generalizability of nanoparticle-vesicle matrix interactions. Anal Bioanal Chem 2010;398:677-88.

119. Nel A, Xia T, Mädler L, Li N. Toxic potential of materials at the nanolevel. Science 2006;311:622-7.

120. Parry MC, Bhabra G, Sood A, Machado F, Cartwright L, Saunders $M$, et al. Thresholds for indirect DNA damage across cellular barriers for orthopaedic biomaterials. Biomaterials 2010;31:4477-83.

121. Kagan VE, Konduru NV, Feng W, Allen BL, Conroy J, Volkov Y, et al. Carbon nanotubes degraded by neutrophil myeloperoxidase induce less pulmonary inflammation. Nat Nano 2010;5:354-9.

122. Dell'Orco D, Lundqvist M, Cedervall T, Linse S. Delivery success rate of engineered nanoparticles in the presence of the protein corona: a systems-level screening. Nanomed: Nanotech Bio Med 2012;8:1271-81.

123. Shannahan JH, Lai X, Ke PC, Podila R, Brown JM, Witzmann FA. Silver nanoparticle protein corona composition in cell culture media. PLoS One 2013;8:e74001.

124. Kneipp K, Haka AS, Kneipp H, Badizadegan K, Yoshizawa N, Boone C, et al. Surface-enhanced raman spectroscopy in single living cells using gold nanoparticles. Appl Spectrosc 2002;56:150-4.

125. Kneipp J, Kneipp H, McLaughlin M, Brown D, Kneipp K. In vivo molecular probing of cellular compartments with gold. nanoparticles and nanoaggregates. Nano Lett 2006;6: 2225-31.

126. Kneipp J, Kneipp H, Rajadurai A, Redmond RW, Kneipp K. Optical probing and imaging of live cells using SERS labels. J Raman Spectrosc 2009;40:1-5.

127. Kneipp J, Kneipp H, Rice WL, Kneipp K. Optical probes for biological applications based on surface-enhanced Raman scattering from indocyanine green on gold nanoparticles. Anal Chem 2005;77:2381-5.

128. Kneipp J, Kneipp H, Wittig B, Kneipp K. Novel optical nanosensors for probing and imaging live cells. J Phys Chem C 2010;114:7421-6.

129. Dorney J, Bonnier F, Garcia A, Casey A, Chambers G, Byrne HJ. Identifying and localizing intracellular nanoparticles using raman spectroscopy. Analyst 2012;137:1111-9.

130. Kendall K, Du S, Morris S, Sweet S. Virus concentration and adhesion measured by laser tracking. J Adhesion 2010;86:1029-40.

131. Johnson KL, Kendall K, Roberts AD. Surface energy and the contact of elastic solids. Proc R Soc London 1971;A324:301-13.

132. Rong W, Ding W, Mädler L, Ruoff RS, Friedlander SK. Mechanical properties of nanoparticle chain aggregates by combined AFM and SEM: isolated aggregates and networks. NanoLett 2006;6:2646-55.

133. Kendall K, Kendall M, Rehfeldt F. Adhesion of Cells, Viruses and Nanoparticles. Dordrecht, Heidelberg, London, New York: Springer, 2011.

134. Medina-Kauwe LK. “Alternative” endocytic mechanisms exploited by pathogens: new avenues for therapeutic delivery? Adv Drug Deliv Rev 2007;59:798-809.

135. Hood L, Heath JR, Phelps ME, Lin B. Systems biology and new technologies enable predictive and preventative medicine. Science 2004;306:640-3. 
136. Janes KA, Albeck JG, Gaudet S, Sorger PK, Lauffenburger DA, Yaffe MB. A systems model of signaling identifies a molecular basis set for cytokine-induced apoptosis. Science 2005;310:1646-53.

137. Ito T, Chiba T, Yoshida M. Exploring the protein interactome using comprehensive two-hybrid projects. Trends Biotechnol. 2001;19(10 Suppl):S23-7.

138. Stelzl U, Worm U, Lalowski M, Haenig C, Brembeck FH, Goehler $\mathrm{H}$, et al. A human protein-protein interaction network: a resource for annotating the proteome. Cell 2005;122:957-68.

139. Xia XR, Monteiro-Riviere NA, Riviere JE. An index for characterization of nanomaterials in biological systems. Nat Nanotechnol 2010;5:671-5.

140. Saptarshi SR, Duschl A, Lopata AL. Interaction of nanoparticles with proteins: relation to bio-reactivity of the nanoparticle. J Nanobiotechnol 2013;11:26.

141. Lynch I, Dawson KA, Linse S. Detecting cryptic epitopes created. by nanoparticles. Science Signaling 2006;2006:14.

142. Wilkinson K, Ekstrand-Hammarström B, Ahlinder L, Guldevall K, Pazik R, Kępiński L, et al. Visualization of custom-tailored iron oxide nanoparticles chemistry, uptake, and toxicity. Nanoscale 2012;4:7383-93.
143. Röcker C, Pötzl M, Zhang F, Parak WJ, Nienhaus GU. A quantitative fluorescence study of protein monolayer. formation on colloidal nanoparticles. Nat Nanotechnol 2009;4:577-80.

144. Tenzer S, Docter D, Kuharev J, Musyanovych A, Fetz V, Hecht R, et al. Rapid formation of plasma protein corona critically affects nanoparticle pathophysiology. Nat Nanotechnol 2013;8:772-81.

145. European Academies Science Advisory Council, E., and European Commission Joint Research Centre (JRC) Joint EASAC-JRC Report, September 2011; 2011.

146. Scientific Committee on Emerging and Newly Identified Health Risks SCENIHR Opinion on Risk Assessment of Products of Nanotechnologies; 2009.

147. van der Bij S, Schaake E, Koffijberg H, Burgers JA, de Mol BA, Moons KG. Markers for the non-invasive diagnosis of mesothelioma: a systematic review. Br J Cancer 2011;104: 1325-33.

148. Lynch I. Are there generic mechanisms governing interactions between nanoparticles and cells? Epitope mapping the outer layer of the protein-material interface. Physica A 2007;373:511-20. 